\title{
Traveling Wave Resonance and Simplified Analysis Method for Long-Span Symmetrical Cable-Stayed Bridges under Seismic Traveling Wave Excitation
}

\author{
Zhong-ye Tian and Meng-lin Lou \\ State Key Laboratory of Disaster Reduction in Civil Engineering, Tongji University, Shanghai 200092, China \\ Correspondence should be addressed to Zhong-ye Tian; 10tzy@tongji.edu.cn
}

Received 12 June 2014; Revised 18 October 2014; Accepted 22 October 2014; Published 31 December 2014

Academic Editor: Longjun Dong

Copyright ( 2014 Z.-y. Tian and M.-l. Lou. This is an open access article distributed under the Creative Commons Attribution License, which permits unrestricted use, distribution, and reproduction in any medium, provided the original work is properly cited.

\begin{abstract}
The seismic responses of a long-span cable-stayed bridge under uniform excitation and traveling wave excitation in the longitudinal direction are, respectively, computed. The numerical results show that the bridge's peak seismic responses vary significantly as the apparent wave velocity decreases. Therefore, the traveling wave effect must be considered in the seismic design of long-span bridges. The bridge's peak seismic responses do not vary monotonously with the apparent wave velocity due to the traveling wave resonance. A new traveling wave excitation method that can simplify the multisupport excitation process into a two-support excitation process is developed.
\end{abstract}

\section{Introduction}

Because of the ever-increasing economic and technological developments, long-span cable-stayed bridges have increased in both number and span lengths, examples include the Tatara Bridge, built in Japan in 1999 with a main span of $890 \mathrm{~m}$, the Sutong Bridge, built in China in 2008 with a main span of $1088 \mathrm{~m}$, and the Russky Island Bridge, built in Russia in 2012 with a main span of $1104 \mathrm{~m}$. The evaluation of seismic performance becomes particularly important for these types of structures, as the distances between their multiple support points are great, sometimes even greater than the seismic wavelength. Therefore, a uniform excitation evaluation method is not suitable and the traveling wave effect must be considered [1]. Many scholars have conducted studies on the seismic performance of these structures. References [2-8] studied the features of seismic responses of long-span cablestayed bridges under uniform excitation and multisupport excitations, respectively. Allam et al. made researches using random vibration method [9-12]. Researchers have also explored effective seismic control strategies for cable-stayed bridges [13-16] and experimental tests have been carried out
$[17,18]$. The methods for obtaining seismic sources play very important roles for investigating safety performance of cablestayed bridges as well, and Dong and Li have conducted primitive work in this area [19-23]. They optimized and simplified the sensor location coordinates to find the analytical solution of the acoustic emission/microseismic source location coordinates. They also developed a new location method using P-wave and S-wave arrivals for unknown velocity system to eliminate the location error of monitoring system caused by the measurement deviations of the wave velocity. These research results can be used in the seismic response analysis of cable-stayed bridges for monitoring the seismic location in the future.

But research on the relationship between the structures' seismic response and the apparent wave velocity is insufficient. This paper, by comparing between the seismic responses of a highway bridge under both traveling wave and uniform excitations, demonstrates the seismic response characteristics of long-span cable-stayed bridges under traveling wave excitation and develops a new traveling wave excitation method that can simplify the multisupport excitation process into a two-support excitation process. 


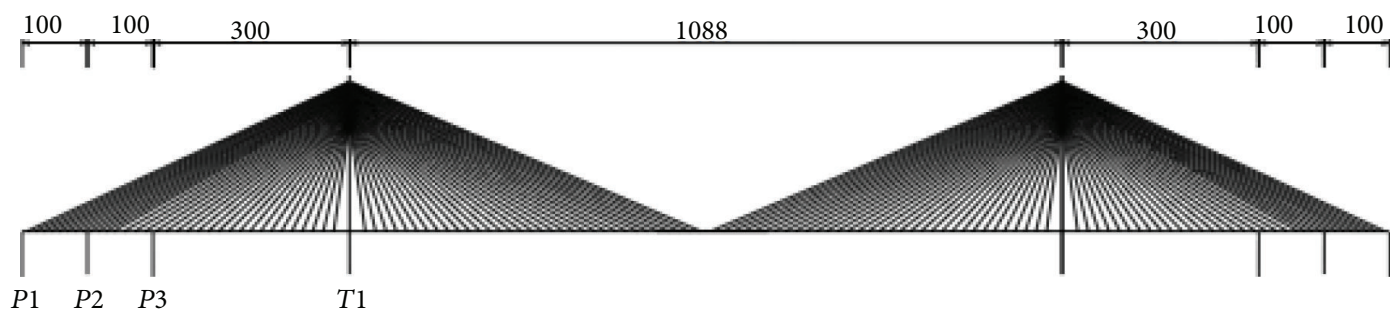

FIGURE 1: Elevation of the highway bridge.

\section{Finite Element Procedures}

2.1. Equations of Motion. The cable-stayed bridge is assumed to be a linear and lumped-mass system with $n$ unconstrained degrees of freedom and $m$ support degrees of freedom. The damping force is assumed to be proportional to the relative velocity $[24,25]$. The equations of motion for such a system subjected to $m$ support motions along the longitudinal direction can be written in the following matrix form [24]:

$$
\begin{gathered}
{\left[\begin{array}{cc}
M & 0 \\
0 & M_{g}
\end{array}\right]\left\{\begin{array}{l}
\ddot{x}(t) \\
\ddot{u}(t)
\end{array}\right\}+\left[\begin{array}{cc}
C & C_{c} \\
C_{c}^{T} & C_{g}
\end{array}\right]\left\{\begin{array}{l}
\dot{x}(t) \\
\dot{u}(t)
\end{array}\right\}} \\
+\left[\begin{array}{cc}
K & K_{c} \\
K_{c}^{T} & K_{g}
\end{array}\right]\left\{\begin{array}{l}
x(t) \\
u(t)
\end{array}\right\}=\left\{\begin{array}{c}
0 \\
f(t)
\end{array}\right\},
\end{gathered}
$$

where $[M],[C]$, and $[K]$ are the $n \times n$ mass, damping, and stiffness matrices associated with the unconstrained degrees of freedom, respectively; $\left[M_{g}\right],\left[C_{g}\right]$, and $\left[K_{g}\right]$ are the $m \times m$ matrices associated with the support degrees of freedom; $\left[M_{c}\right],\left[C_{c}\right]$, and $\left[K_{c}\right]$ are the $n \times m$ coupling matrices associated with both sets of degrees of freedom; $\{\ddot{x}(t)\},\{\dot{x}(t)\}$, and $\{x(t)\}$ refer to the $n$ vectors of absolute accelerations, velocities, and displacements at the unconstrained degrees of freedom; $\{\ddot{u}(t)\},\{\dot{u}(t)\}$, and $\{u(t)\}$ refer to the $m$ vectors of prescribed support accelerations, velocities, and displacements; and $\{f(t)\}$ is the $m$ vector of the reacting forces at the support degrees of freedom.

It is common to decompose the response into pseudostatic and dynamic components [24, 25]; that is,

$$
\{x(t)\}=\left\{x^{s}(t)\right\}+\left\{x^{d}(t)\right\}
$$

where the pseudostatic component, $\left\{x^{s}(t)\right\}$, is the solution to (1) without the inertia and damping terms and is given by

$$
\left\{x^{s}(t)\right\}=-[K]^{-1}\left[K_{c}\right]\{u(t)\}=[R]\{u(t)\}
$$

in which $[R]=-[K]^{-1}\left[K_{c}\right]$ denotes the influence matrix. Substituting (2) and (3) into (1), while neglecting the damping forces multiplied by $\{\dot{u}(t)\}$ because they are typically much smaller than the inertia forces on the same side, the dynamic component of the response is obtained in the differential form

$$
\begin{gathered}
{[M]\left\{\ddot{x}^{d}(t)\right\}+[C]\left\{\dot{x}^{d}(t)\right\}+[K]\left\{x^{d}(t)\right\}} \\
=-[M][R]\{\ddot{u}(t)\} .
\end{gathered}
$$

The multisupport acceleration excitation $\{\ddot{u}(t)\}$ in (1) is

$$
\{\ddot{u}(t)\}^{T}=\left\{\left\{\ddot{u}_{1}(t)\right\},\left\{\ddot{u}_{2}(t)\right\}, \ldots,\left\{\ddot{u}_{m}(t)\right\}\right\},
$$

where the seismic acceleration excitation at the $i$ th support is $\left\{\ddot{u}_{i}(t)\right\}^{T}=\left\{\ddot{u}_{i x}(t), \ddot{u}_{i y}(t), \ddot{u}_{i z}(t)\right\}$. If only the seismic excitation in the longitudinal direction is considered, then $\left\{\ddot{u}_{i}(t)\right\}^{T}=$ $\left\{\ddot{u}_{g}\left(t-\left(\Delta_{i} / v_{a}\right)\right), 0,0\right\}$, where $\ddot{u}_{g}(t)$ refers to the time history of the ground motion, $\Delta_{i}$ denotes the horizontal distance between the $i$ th and the first station, $v_{a}$ is the surface apparent wave velocity, and $m$ becomes the number of supports.

2.2. Description of the Bridge and Support Excitations. We consider a highway bridge with an elevation as shown in Figure 1. The bridge is a long-span symmetrical cable-stayed structure with double towers, double cable planes, and a total length of $2088 \mathrm{~m}$. The distances between the adjacent piers and towers are $100 \mathrm{~m}, 100 \mathrm{~m}, 300 \mathrm{~m}, 1088 \mathrm{~m}, 300 \mathrm{~m}, 100 \mathrm{~m}$, and $100 \mathrm{~m}$ from left to right. The inverted Y-shaped main tower is 300.4 meters high. Flat streamlined steel box girders with a width of $35.4 \mathrm{~m}$ are used for the deck beams. The longitudinal slope is $1.5 \%$ and the main span lies in a circular curve with $R=36300 \mathrm{~m}$. Deck beams are connected with the piers and towers by using sliding supports and dynamic dampers, which are used to confine the rated travel in a longitudinal direction, thus making the bridge a floating system. High strength parallel wire cable is adopted. The finite element method is employed and the beam element is used to simulate the piers, towers, and deck beams. The link element is used to simulate the cables. The beam element is linear, twonode, and three-dimensional. It has six degrees of freedom at each node and is based on Timoshenko beam theory. The link element is linear, two-node, and three-dimensional and has three translational degrees of freedom at each node. The bridge is discretized into 2050 elements with 10622 degrees of freedom.

Nine sets of seismic acceleration data are used as excitation in the analysis, which are all obtained from the seismic safety evaluation of the specific engineering site. Three sets are marked as $a_{1}, a_{2}$, and $a_{3}$ for an exceeding probability of $2 \%$ in 50 years; three sets are marked as $b_{1}, b_{2}$, and $b_{3}$ for an exceeding probability of $2 \%$ in 100 years, and the other three sets are marked as $c_{1}, c_{2}$, and $c_{3}$ for an exceeding probability of $10 \%$ in 100 years. The time steps of the acceleration histories are all $0.02 \mathrm{~s}$. The motion at each support and the propagation of the waves are all assumed to be in longitudinal direction. 


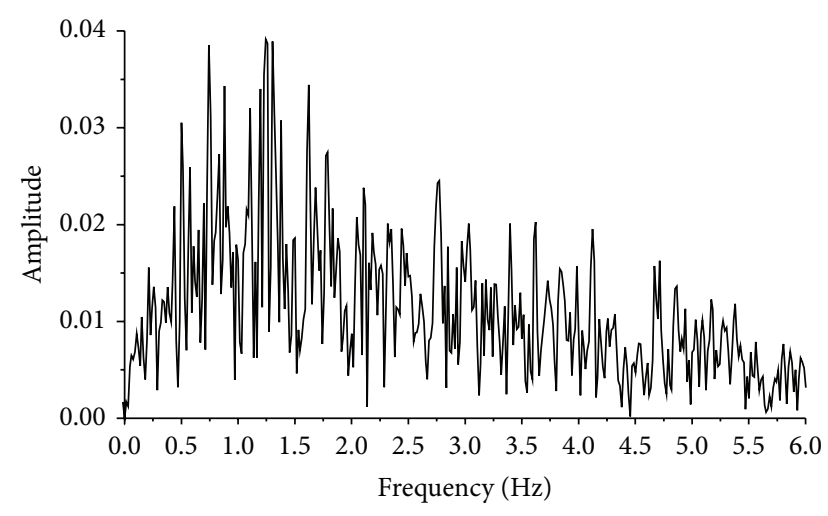

FIGURE 2: Fourier amplitude of $a_{1}$.

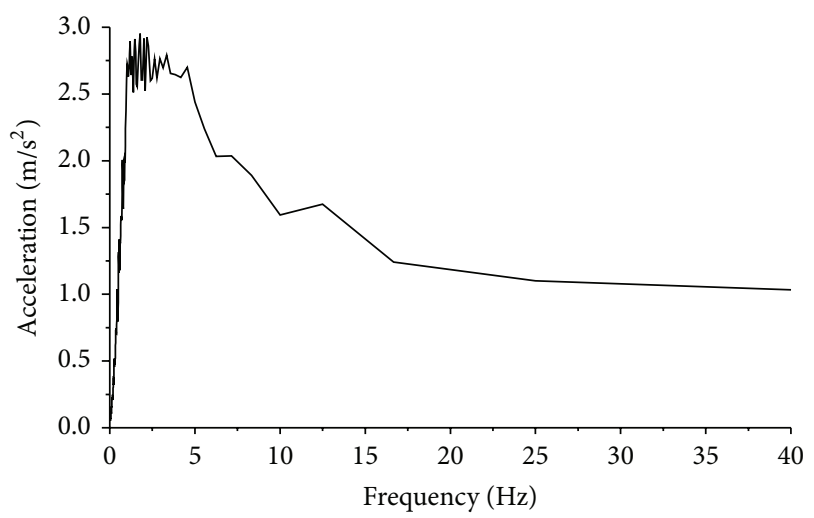

Figure 3: Acceleration response spectrum of $a_{1}$.

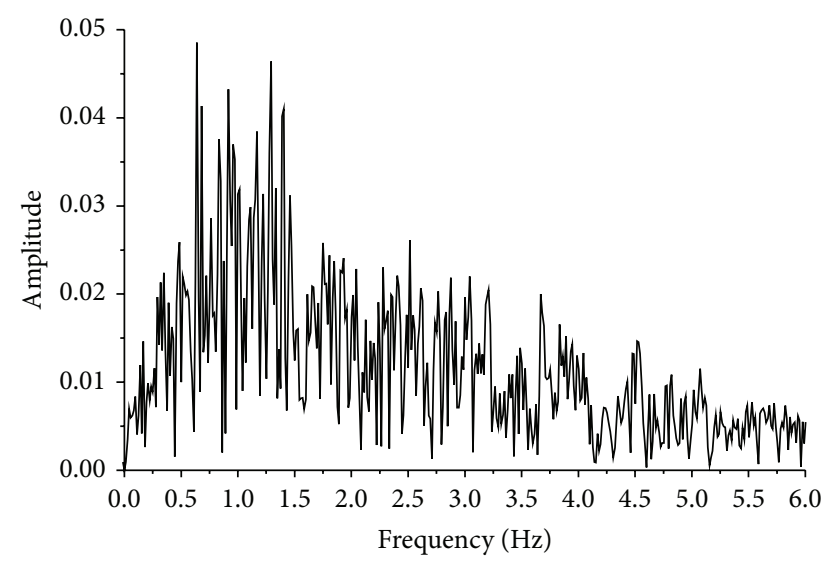

FIgURE 4: Fourier amplitude of $b_{1}$.

Figures 2, 3, 4, 5, 6, and 7 show the Fourier amplitude spectra and the acceleration response spectra of $a_{1}, b_{1}$, and $c_{1}$.

\section{Natural Vibration Analysis of the Bridge Model}

The free vibration analysis of the bridge is conducted and the first 14 natural frequencies are shown in Table 1.

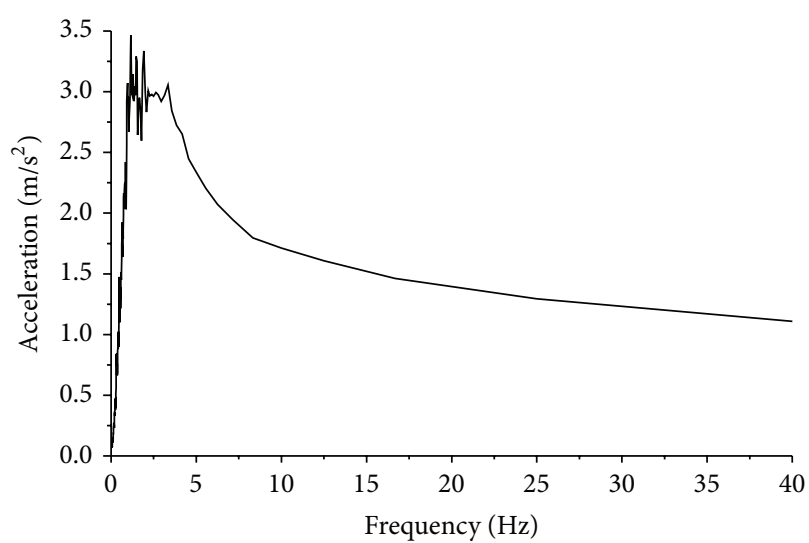

Figure 5: Acceleration response spectrum of $b_{1}$.

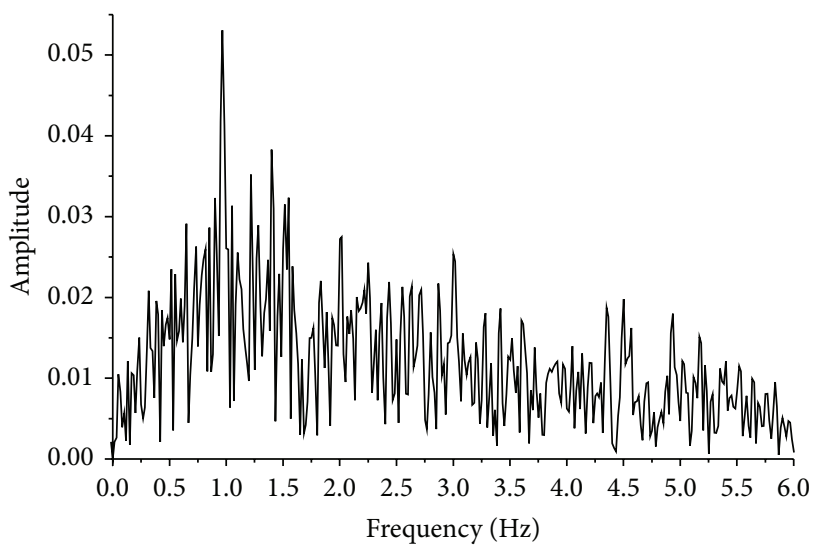

Figure 6: Fourier amplitude of $c_{1}$.

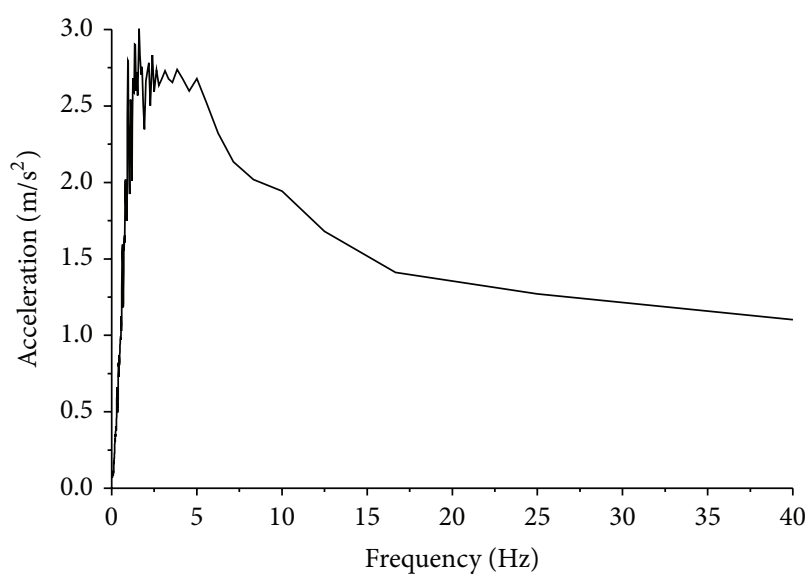

FIGURE 7: Acceleration response spectrum of $c_{1}$.

\section{Numerical Analysis for the Seismic Responses of the Bridge}

To study the influence of the traveling wave effect on the seismic response of the bridge, five values of apparent wave velocity $c$ are considered: $500 \mathrm{~m} / \mathrm{s}, 1000 \mathrm{~m} / \mathrm{s}, 2000 \mathrm{~m} / \mathrm{s}$, $3000 \mathrm{~m} / \mathrm{s}$, and $5000 \mathrm{~m} / \mathrm{s}$; in addition, uniform excitation can 
TABLE 1: Frequencies $(\mathrm{Hz})$ and characteristics of the first 14 modes of the cable-stayed bridge.

\begin{tabular}{lcl}
\hline Order & Frequency & Characteristic \\
\hline 1 & 0.0656 & Longitudinal floating \\
2 & 0.1004 & Transverse symmetric bending of deck beam \\
3 & 0.1779 & Vertical symmetric bending of deck beam \\
4 & 0.2195 & Vertical antisymmetric bending of deck beam \\
5 & 0.2819 & Transverse antisymmetric bending of deck beam \\
6 & 0.3083 & Vertical symmetric bending of deck beam + longitudinal bending of towers in opposite direction \\
7 & 0.3718 & Vertical antisymmetric bending of deck beam + longitudinal bending of towers in the same direction \\
8 & 0.4175 & Vertical symmetric bending of deck beam + longitudinal bending of towers in opposite direction \\
9 & 0.4663 & Transverse bending of towers in the same direction \\
10 & 0.4678 & Transverse bending of towers in opposite direction \\
11 & 0.4692 & Vertical antisymmetric bending of deck beam + longitudinal bending of towers in the same direction \\
12 & 0.5066 & Vertical symmetric bending of deck beam + longitudinal bending of towers in opposite direction \\
13 & 0.5214 & Torsion and transverse symmetric bending of deck beam \\
14 & 0.5534 & Vertical antisymmetric bending of deck beam \\
\hline
\end{tabular}

TABLE 2: Relationships between the main span, structural natural frequencies, apparent wave velocity, and wavelength.

\begin{tabular}{|c|c|c|c|c|c|c|c|c|c|c|}
\hline \multirow[b]{3}{*}{ Order } & \multirow{3}{*}{ Mode } & \multirow[b]{3}{*}{$f_{i}(\mathrm{~Hz})$} & \multicolumn{8}{|c|}{ Surface apparent wave velocity } \\
\hline & & & \multicolumn{2}{|c|}{$c=1712 \mathrm{~m} / \mathrm{s}$} & \multicolumn{2}{|c|}{$c=1100 \mathrm{~m} / \mathrm{s}$} & \multicolumn{2}{|c|}{$c=1000 \mathrm{~m} / \mathrm{s}$} & \multicolumn{2}{|c|}{$c=900 \mathrm{~m} / \mathrm{s}$} \\
\hline & & & $\lambda_{i}(\mathrm{~m})$ & $L / \lambda_{i}$ & $\lambda_{i}(\mathrm{~m})$ & $L / \lambda_{i}$ & $\lambda_{i}(\mathrm{~m})$ & $L / \lambda_{i}$ & $\lambda_{i}(\mathrm{~m})$ & $L / \lambda_{i}$ \\
\hline 8 & Symmetric in longitudinal direction & 0.41747 & & & & & 2395 & 0.45 & 2156 & 0.50 \\
\hline 12 & Symmetric in longitudinal direction & 0.50662 & & & 2171 & 0.50 & 1974 & 0.55 & & \\
\hline 26 & Symmetric in longitudinal direction & 0.78681 & 2176 & 0.50 & & & & & & \\
\hline
\end{tabular}

also be observed as a case, where $c=\infty$. Reference [26] indicated that the traveling wave resonance effect existed in the seismic response of long-span arch bridges when the apparent wave velocity obtained specific values. To see if this phenomenon exists in the seismic response of long-span double-tower cable-stayed bridges, three additional values of apparent wave velocity are adopted: $1712 \mathrm{~m} / \mathrm{s}, 1100 \mathrm{~m} / \mathrm{s}$, and $900 \mathrm{~m} / \mathrm{s}$; the theoretical foundation is provided below.

If we assume the longitudinal support excitation to be a sine wave with the same frequency as the $i$ th natural frequency of the structure, then the wavelength of the sine wave would be $\lambda_{i}=c / f_{i}$, with $c$ and $f_{i}$ denoting the surface apparent wave velocity and the $i$ th natural frequency of the structure, respectively. In the case of uniform longitudinal excitation, the wavelength is equivalent to $\infty$, which means that the support motions of the two main towers are antisymmetric; therefore, the seismic response of the symmetric modes of the structure will not be excited. But, in the case of longitudinal traveling wave excitation, if a specific surface apparent wave velocity can make the main span $L=0.5 \lambda_{i}$, then the support motions of the two main towers would be equal and opposite, thus forming longitudinal symmetric excitation for the two towers. If the $i$ th mode shape is symmetric, then it will be excited along with other symmetric modes and will remain in a resonance state, thus maximizing its modal response.

Based on a free vibration analysis of the bridge, we know that the 8 th, 12th, and 26th modes are symmetric. Figures 8, 9, and 10 show the mode shapes and Table 2 shows

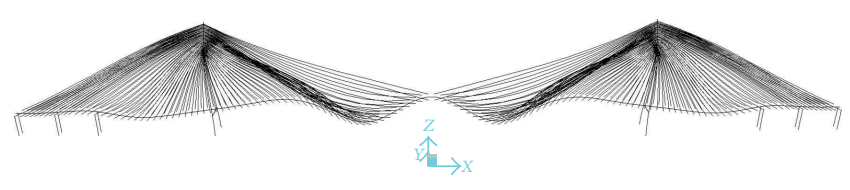

Figure 8: The 8th mode shape of the bridge.

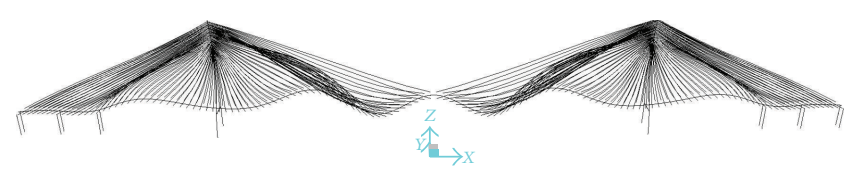

FIgURE 9: The 12th mode shape of the bridge.

the relationships between the main span, the structural natural frequencies, the apparent wave velocity, and the wavelength.

We call this phenomenon as the traveling wave resonance. At a specific apparent wave velocity, the span of a symmetric structure attains sufficiently close to an integral multiple of the half-wavelength of the excitation wave, and the frequency of the excitation becames the frequency of one of the structural modes. When the excitation and the mode are both symmetric or antisymmetric, the mode reaches a resonance state and its contribution to the response of the structure is maximized. 
TABLE 3: Traveling wave effect influence coefficient (\%) for seismic responses under excitation of $a_{1}$.

\begin{tabular}{|c|c|c|c|c|c|c|c|c|}
\hline Apparent wave velocity $(\mathrm{m} / \mathrm{s})$ & 5000 & 3000 & 2000 & 1712 & 1100 & 1000 & 900 & 500 \\
\hline$U_{t}$ & -2.7 & -3.8 & -2.8 & -2.4 & -3.9 & -4.6 & -6.0 & -8.5 \\
\hline$A_{t}$ & -19.2 & -20.8 & -15.0 & -12.1 & -14.1 & -15.9 & -16.8 & -17.4 \\
\hline$U_{b}$ & -6.5 & -12.2 & -17.9 & -19.5 & -14.5 & -11.1 & -7.3 & -18.3 \\
\hline$U_{c}$ & -4.6 & -9.4 & -14.5 & -16.1 & -12.9 & -10.3 & -7.0 & -18.8 \\
\hline$F_{P 1}$ & -3.4 & 5.1 & 4.6 & -1.2 & -12.8 & -3.6 & 5.5 & -13.4 \\
\hline$M_{P 1}$ & 0.0 & 0.0 & 0.0 & 0.0 & 0.0 & 0.0 & 0.0 & 0.0 \\
\hline$S_{P 1}$ & 0.0 & 0.0 & 0.0 & 0.0 & 0.0 & 0.0 & 0.0 & 0.0 \\
\hline$F_{P 2}$ & -12.4 & -23.9 & -26.5 & -22.9 & -17.3 & -17.5 & -17.7 & -18.2 \\
\hline$M_{P 2}$ & 0.0 & 0.0 & 0.0 & 0.0 & 0.0 & 0.0 & 0.0 & 0.0 \\
\hline$S_{P 2}$ & 0.0 & 0.0 & 0.0 & 0.0 & 0.0 & 0.0 & 0.0 & 0.0 \\
\hline$F_{P 3}$ & 4.9 & 7.8 & 9.4 & 10.7 & 17.9 & 19.1 & 18.9 & 1.4 \\
\hline$M_{P 3}$ & 0.0 & 0.0 & 0.0 & 0.0 & 0.0 & 0.0 & 0.0 & 0.0 \\
\hline$S_{P 3}$ & 0.0 & 0.0 & 0.0 & 0.0 & 0.0 & 0.0 & 0.0 & 0.0 \\
\hline$F_{T 1}$ & 5.4 & 12.5 & 21.2 & 26.3 & 38.8 & 40.0 & 39.8 & -8.9 \\
\hline$M_{T 1}$ & -6.9 & -12.8 & -18.6 & -19.9 & -14.7 & -11.3 & -7.1 & -18.4 \\
\hline$\underline{S_{T 1}}$ & 3.3 & 5.1 & 4.1 & 2.3 & -5.6 & -7.4 & -8.5 & 6.7 \\
\hline
\end{tabular}

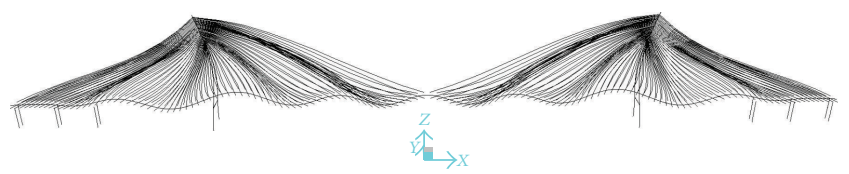

FIGURE 10: The 26th mode shape of the bridge.

When the frequency of the resonant mode is within the predominant frequencies of the ground motion, the contribution maximization phenomenon will be more significant. It may increase or decrease the structural response depending on the orientation combination of the modal superposition, and the results will vary with different ground motions.

The structural seismic response may reach an extreme value, or even maxima and minima, at specific apparent wave velocities because of the traveling wave resonance. Therefore, significant importance should be attached to this phenomenon.

4.1. Seismic Responses of the Bridge. We examine the peak values of the following structural responses: the crosssectional axial forces, bending moments, and shear forces at the bottoms of piers $P 1, P 2, P 3$, and main tower $T 1$ (see Figure 1), denoted by $F_{P 1}, M_{P 1}, S_{P 1}, F_{P 2}, M_{P 2}, S_{P 2}, F_{P 3}, M_{P 3}$, $S_{P 3}, F_{T 1}, M_{T 1}$, and $S_{T 1}$; the relative displacement between the connection node of tower $T 1$ and the beam and the node at the bottom of tower $T 1$, denoted by $U_{c}$; the relative displacement between the top and bottom nodes of the finite element, which is at the bottom of tower $T 1$, referred to as $U_{b}$; the relative displacement between the top and bottom nodes on tower $T 1$ and the absolute acceleration of the top node of tower $T 1$, referred to as $U_{t}$ and $A_{t}$.

To clearly compare the peak values of structural seismic responses under uniform excitation and traveling wave excitation, we define the traveling wave effect influence coefficient $e_{t}=\left(\left(m_{t}-m_{u}\right) / m_{u}\right) \times 100 \%$, where $m_{t}$ denotes the peak response under traveling wave excitation, and $m_{u}$ refers to the peak response under uniform excitation. If $e_{t}$ is a positive number, then the structural response increases when considering the traveling wave effect; if not, then it decreases.

The results show that structural seismic responses vary in a similar pattern under the excitations of the nine different sets of seismic acceleration data. Due to space limitations in this paper, only the results under the excitations of $a_{1}, b_{1}$, and $c_{1}$ are listed (See Tables 3, 4, and 5); however, the conclusions are based on all computing results.

The results show that responses considering the traveling wave effect significantly differ from those under uniform excitation. For example, let us compare the results in the case where $c=1000 \mathrm{~m} / \mathrm{s}$ with those in the case of uniform excitation: under the excitation of $a_{1}, F_{P 3}$ increases by $19.1 \%$, $M_{T 1}$ decreases by $11.3 \%$, and $F_{T 1}$ increases by $40 \%$. And under the excitation of $b_{1}, F_{T 1}, M_{Y 1}$, and $S_{T 1}$ are amplified by $18.4 \%, 11.1 \%$, and $8.7 \%$, respectively. These responses threaten structural safety and should be given sufficient attention in the seismic design of long-span cable-stayed bridges.

However, the seismic responses of the bridge do not always follow the same changing rules with the decrease of the surface apparent wave velocity. The responses may be amplified under the excitation of one set of ground motions but may be reduced under the excitation of another set. Even when the input is certain, some responses may remain the same, some may be amplified, and others may be reduced. For instance, the cross-sectional bending moment and shear force responses at the bottom of the piers are barely influenced by the wave passage effect because the bridge is a floating system (see Section 2.2). The longitudinal displacement responses of the nodes on each pier almost fully depend on the pier support motion itself; if only the ground motion remains constant, then the longitudinal displacements of the nodes will not change and neither will the bending moments nor the shear forces. The time histories of the responses will be slightly translated, because the starting time of the support motion varies with the apparent wave velocity (see Figure 11). As another example, $U_{t}$ is reduced under the excitation of 
TABLE 4: Traveling wave effect influence coefficient (\%) for seismic responses under excitation of $b_{1}$.

\begin{tabular}{lcccccccc}
\hline Apparent wave velocity $(\mathrm{m} / \mathrm{s})$ & 5000 & 3000 & 2000 & 1712 & 1100 & 1000 & 900 & 500 \\
\hline$U_{t}$ & 0.1 & -0.1 & -1.4 & -2.5 & -5.9 & -7.2 & -8.7 & -11.4 \\
$A_{t}$ & -11.5 & -15.9 & -10.0 & -3.9 & -4.2 & -12.7 & -18.2 & 0.4 \\
$U_{b}$ & -8.8 & -15.6 & -21.2 & -21.8 & -19.1 & -18.2 & -17.9 & -17.9 \\
$U_{c}$ & -6.4 & -12.3 & -18.1 & -19.6 & -18.4 & -17.7 & -17.2 & -17.1 \\
$F_{P 1}$ & -1.9 & -12.2 & -29.3 & -21.5 & -6.6 & -8.2 & 0.4 & -25.2 \\
$M_{P 1}$ & 0.0 & 0.0 & 0.0 & 0.0 & -0.1 & -0.1 & -0.1 & -0.1 \\
$S_{P 1}$ & 0.0 & 0.0 & -1.0 & 0.0 & 0.0 & 0.0 & 0.1 \\
$F_{P 2}$ & 8.9 & 13.9 & 15.1 & 9.3 & 10.2 & 10.2 & 15.3 \\
$M_{P 2}$ & 0.0 & 0.1 & 0.1 & 0.0 & 0.0 & 0.0 & 0.1 \\
$S_{P 2}$ & 0.0 & 0.0 & 0.0 & 0.0 & 0.0 & 0.0 & 0.0 \\
$F_{P 3}$ & -4.8 & -5.5 & 0.8 & 1.5 & -8.2 & -13.2 & -20.0 \\
$M_{P 3}$ & 0.0 & 0.1 & 0.1 & 0.0 & 0.0 & 0.0 & 0.0 \\
$S_{P 3}$ & 0.0 & 0.0 & 0.0 & 0.0 & 0.0 & 0.0 & 0.0 \\
$F_{T 1}$ & 9.2 & 26.3 & 48.1 & 55.2 & 51.2 & 42.8 & -7.0 \\
$M_{T 1}$ & -9.4 & -16.2 & -21.3 & -22.0 & -19.0 & -18.2 & -18.2 & -0.1 \\
$S_{T 1}$ & 0.1 & 1.7 & -3.7 & -10.7 & -12.5 & -13.7 & -15.5 & -0.1 \\
\hline
\end{tabular}

TABLE 5: Traveling wave effect influence coefficient (\%) for seismic responses under excitation of $c_{1}$.

\begin{tabular}{|c|c|c|c|c|c|c|c|c|}
\hline Apparent wave velocity (m/s) & 5000 & 3000 & 2000 & 1712 & 1100 & 1000 & 900 & 500 \\
\hline$\overline{U_{t}}$ & -1.3 & -1.3 & -1.3 & -1.5 & -2.8 & -3.2 & -3.9 & -13.4 \\
\hline$A_{t}$ & 1.3 & 3.4 & 14.3 & 17.1 & 15.9 & 13.5 & 12.1 & 9.8 \\
\hline$U_{b}$ & 2.3 & -0.9 & -5.1 & -7.5 & 7.5 & 9.3 & 8.9 & 7.5 \\
\hline$U_{c}$ & -0.4 & -2.4 & -5.5 & -6.3 & 2.0 & 3.9 & 4.4 & 6.6 \\
\hline$F_{P 1}$ & -10.9 & -16.0 & -11.1 & -5.2 & 2.2 & 7.0 & 7.8 & -13.9 \\
\hline$M_{P 1}$ & 0.0 & 0.0 & 0.0 & 0.0 & 0.0 & 0.0 & 0.0 & -0.1 \\
\hline$S_{P 1}$ & 0.0 & 0.0 & 0.0 & 0.0 & 0.0 & 0.0 & 0.0 & 0.1 \\
\hline$F_{P 2}$ & -15.6 & -12.1 & 18.0 & 29.5 & 22.0 & 9.6 & -5.4 & -9.0 \\
\hline$M_{P 2}$ & 0.0 & 0.0 & 0.0 & -0.1 & -0.2 & -0.2 & -0.2 & -0.3 \\
\hline$S_{P 2}$ & 0.0 & 0.0 & 0.0 & 0.0 & -0.1 & -0.1 & -0.1 & -0.2 \\
\hline$F_{P 3}$ & 4.3 & 9.2 & 11.1 & 9.7 & 10.7 & 11.6 & 14.1 & 6.3 \\
\hline$M_{P 3}$ & 0.0 & 0.0 & 0.0 & -0.1 & -0.1 & -0.1 & -0.2 & -0.3 \\
\hline$S_{P 3}$ & 0.0 & 0.0 & 0.0 & 0.0 & 0.0 & 0.0 & 0.0 & 0.1 \\
\hline$F_{T 1}$ & 21.0 & 33.6 & 42.9 & 44.3 & 28.2 & 18.4 & 15.6 & 13.2 \\
\hline$M_{T 1}$ & 3.7 & 0.2 & -7.2 & -4.8 & 9.4 & 11.1 & 10.8 & 7.7 \\
\hline$S_{T 1}$ & 3.1 & 3.9 & 5.0 & 1.6 & 7.9 & 8.7 & 8.7 & 8.7 \\
\hline
\end{tabular}

$a_{1}$ and $b_{1}$ when the wave passage effect is considered, but it is amplified under the excitation of $c_{1}$ when $c=1000 \mathrm{~m} / \mathrm{s}$ and $500 \mathrm{~m} / \mathrm{s}$. Reference [27] drew similar conclusions when analyzing another long-span cable-stayed bridge model.

As for the traveling wave resonance, we can see from Tables 3 through 5 that numerous structural peak responses reach their extreme values, either local maxima or minima, when $c=1712 \mathrm{~m} / \mathrm{s}, 1100 \mathrm{~m} / \mathrm{s}, 1000 \mathrm{~m} / \mathrm{s}$, or $900 \mathrm{~m} / \mathrm{s}$. To make the expression clear and distinct, we graph the response data for which the resonance phenomena are obvious. Figures 12, 13, and 14 are based on the results under the excitation of $a_{1}, b_{1}$, and $c_{1}$, respectively. The dotted lines in the figures reflect the results under uniform excitation, which shows the influence trend of different apparent wave velocities.

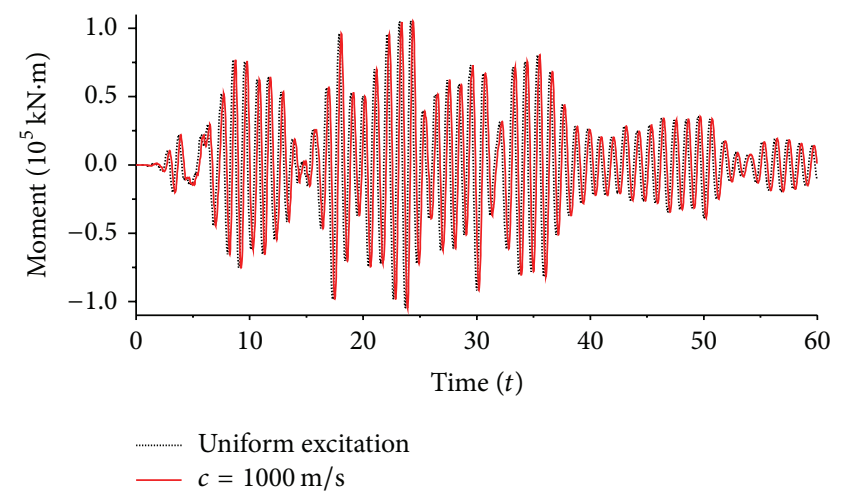

FIgURE 11: Time history of $M_{P 3}$ under the excitation of $c_{3}$. 


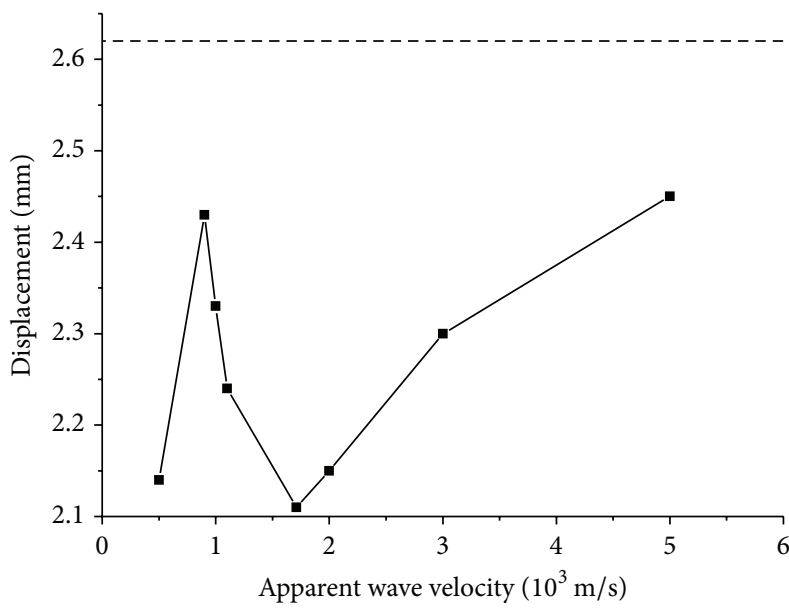

(a) Variation trend of $U_{b}$ with $c$

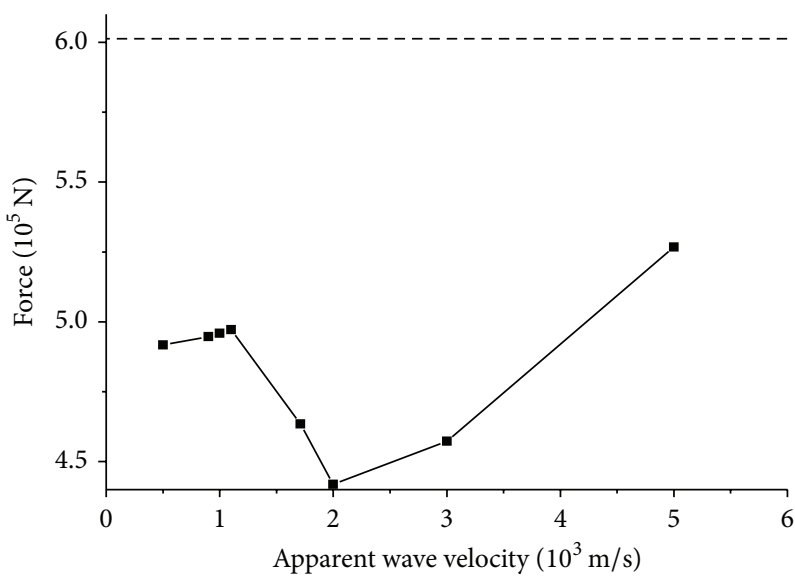

(c) Variation trend of $F_{P 2}$ with $c$

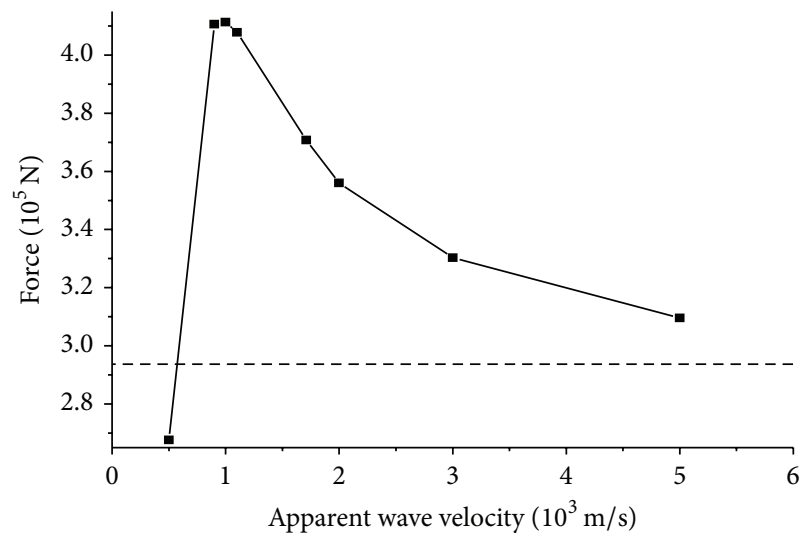

(e) Variation trend of $F_{T 1}$ with $c$

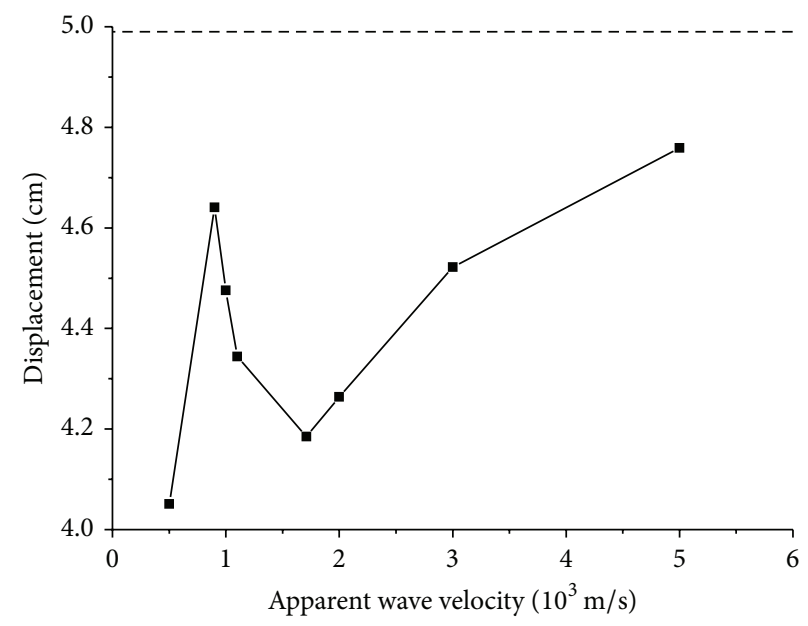

(b) Variation trend of $U_{c}$ with $c$

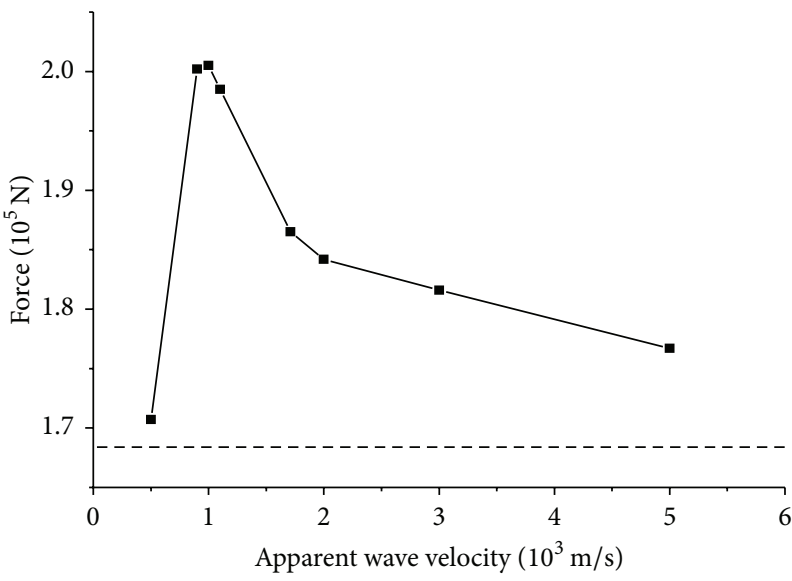

(d) Variation trend of $F_{P 3}$ with $c$

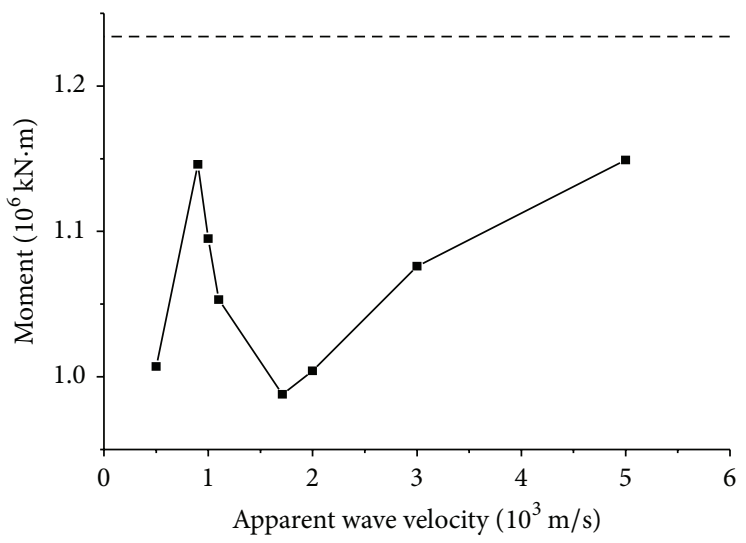

(f) Variation trend of $M_{T 1}$ with $c$

FIGURE 12: Variation trend of peak structural seismic responses with apparent wave velocity under the excitation of $a_{1}$.

Based on Figures 2 through 7 , we can see that $0.50662 \mathrm{~Hz}$ (the 12th natural frequency of the bridge) is within the predominant frequency range of $a_{1}$ and $0.41747 \mathrm{~Hz}$ (the 8 th natural frequency of the bridge) is close to the range; therefore, the resonance phenomenon is evident when $c=1100 \mathrm{~m} / \mathrm{s}, 1000 \mathrm{~m} / \mathrm{s}$, or $900 \mathrm{~m} / \mathrm{s}$ under the excitation of $a_{1}$. For $b_{1}$ and $c_{1}$, the 8th and 12th natural frequencies are beyond the predominant frequency ranges, but the 26th natural frequency $(0.78681 \mathrm{~Hz})$ is within range; therefore, the resonance phenomenon when $c=1712 \mathrm{~m} / \mathrm{s}$ is more remarkable than when $c$ is near 1000 $\mathrm{m} / \mathrm{s}$. 


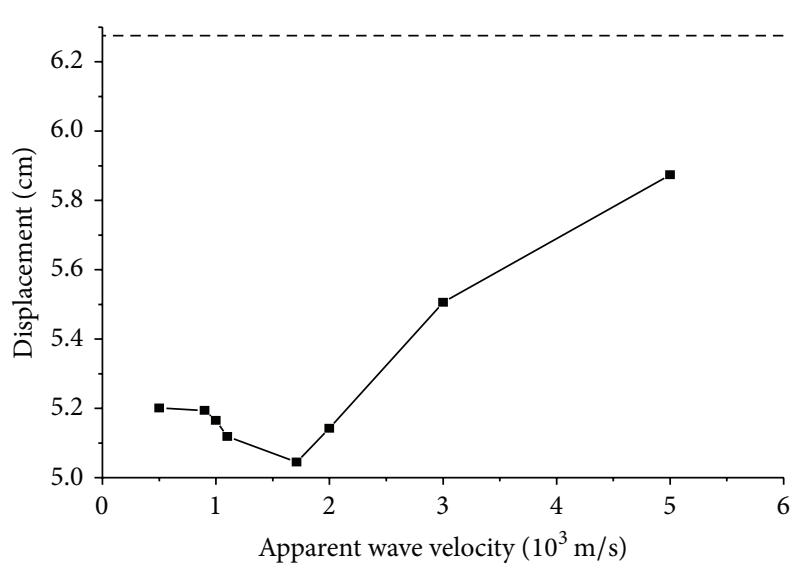

(a) Variation trend of $U_{c}$ with $c$

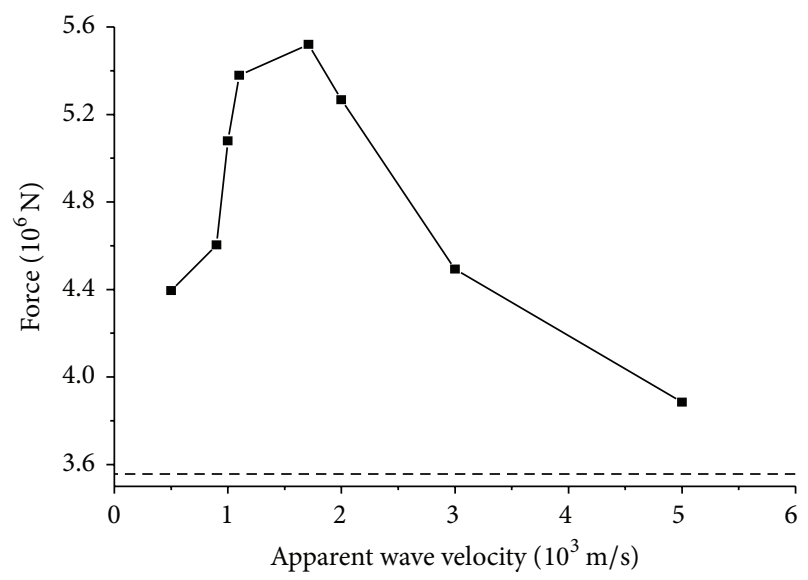

(c) Variation trend of $F_{T 1}$ with $c$

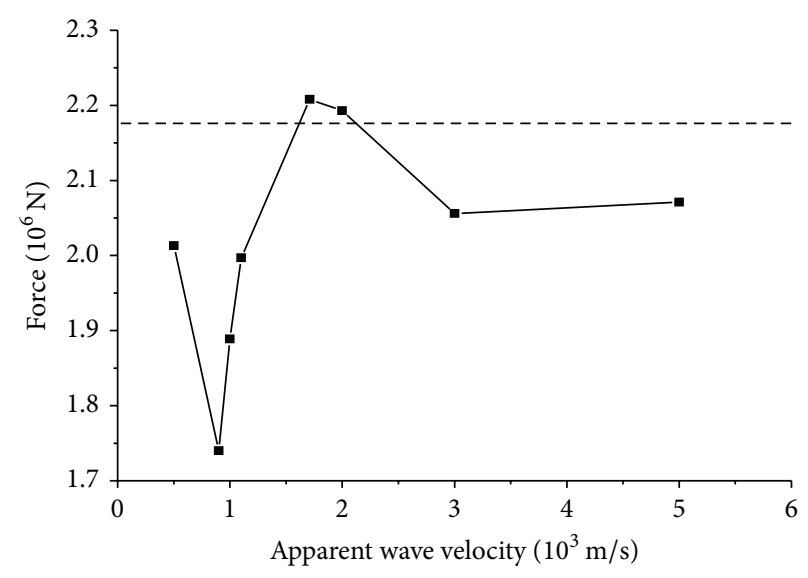

(b) Variation trend of $F_{P 3}$ with $c$

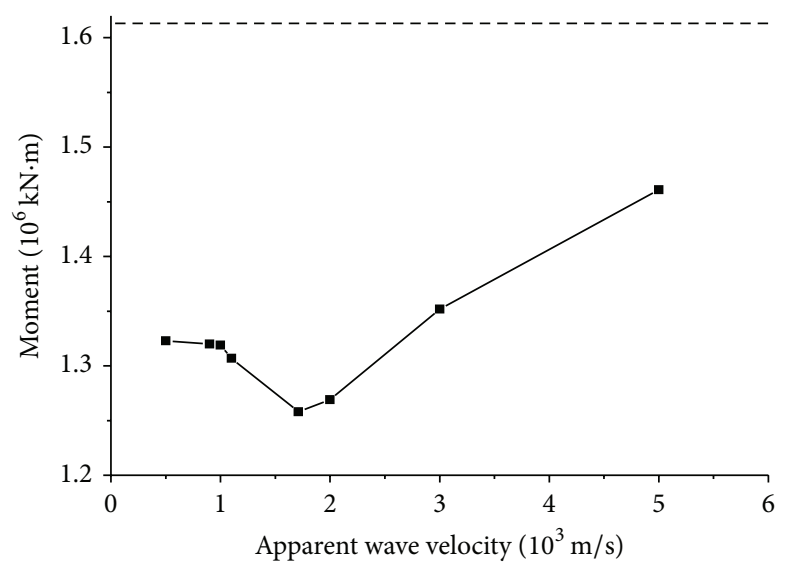

(d) Variation trend of $M_{T 1}$ with $c$

FIGURE 13: Variation trend of peak structural seismic responses with apparent wave velocity under the excitation of $b_{1}$.

\section{Simplified Time History Analysis Method}

When only considering the seismic excitation in the longitudinal direction for the long-span floating system cablestayed bridge shown in Figure 1, that is, the longitudinal displacement responses of nodes on each pier, the crosssectional bending moment and shear force responses of each pier are only affected by the pier support motion and are irrelevant to the traveling time of the seismic wave. However, other structural seismic responses are the results of both the input seismic wave and the traveling wave from one main tower to the other. Therefore, we can ignore the traveling time from the far left pier to the left tower and from the right tower to the far right pier and only consider the wave passage time from the left tower to the right tower. Two different traveling wave excitation methods are used below to discuss the influence of the passage time between the piers and towers on the structural seismic responses.

5.1. Excitation Method 1: Full Traveling Time Excitation. This method is commonly adopted in current practice when the traveling times of the seismic waves between each pair of adjacent supports are considered. The support motions are denoted as $u_{1}(t) \sim u_{8}(t)$, as shown in Figure 15: $u_{1}(t)=$ $u_{g}(t), u_{i}(t)=u_{g}\left(t-\left(\left(x_{i}-x_{1}\right) / c\right)\right)$, where $u_{g}(t)$ denotes the ground motion and $x_{i}$ is the longitudinal coordinate of the ith support.

5.2. Excitation Method 2: Grouping Uniform Excitation. The traveling time from the left-most pier to the left tower and that from the right-most tower to the far right pier are ignored. We assign the three left piers and the left tower to the left group and utilize the uniform excitation method. The three right piers and the right tower are assigned to the right group and are also exposed to uniform excitation. Only the traveling times between the two towers are considered, as shown in Figure 16: $u_{l}(t)=u_{g}(t)$ and $u_{r}(t)=u_{g}(t-(1088 / c))$.

5.3. Comparison of the Results. We define the relative error $e=\left(\left(m_{2}-m_{1}\right) / m_{1}\right) \times 100 \%$ to compare the peak seismic responses computed with the two different excitation methods, where $m_{2}$ and $m_{1}$ refer to the peak responses calculated using excitation method 2 and method 1, respectively.

Figure 17 shows the time histories of $F_{P 2}$ under the excitation of $c_{3}$ when $c=5000 \mathrm{~m} / \mathrm{s}$ and $1000 \mathrm{~m} / \mathrm{s}$. We can see that the time histories resulting from the two excitation 


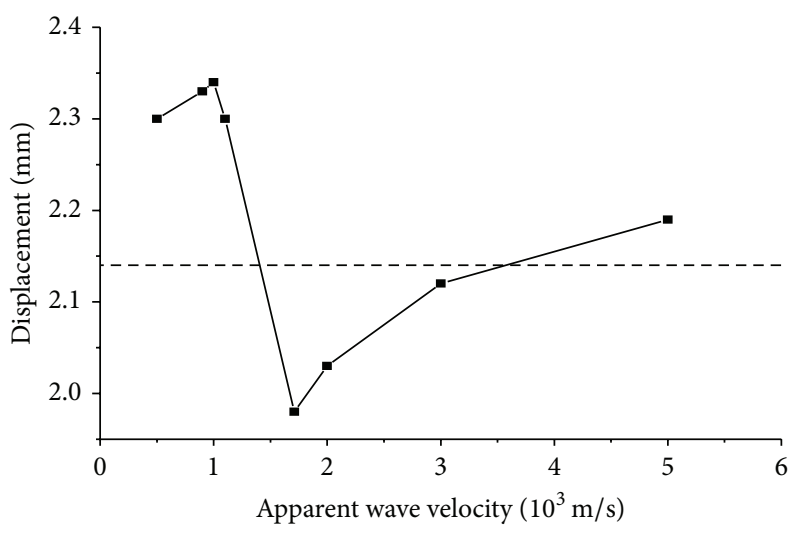

(a) Variation trend of $U_{b}$ with $c$

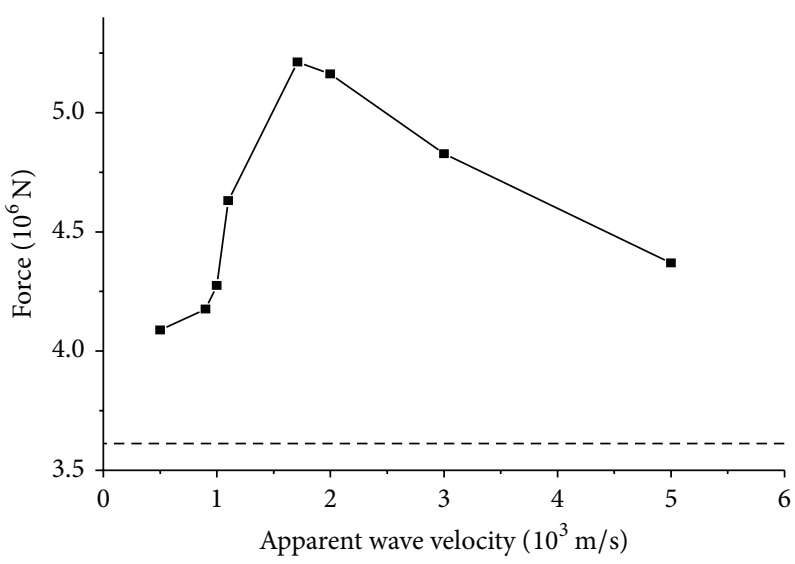

(c) Variation trend of $F_{T 1}$ with $c$

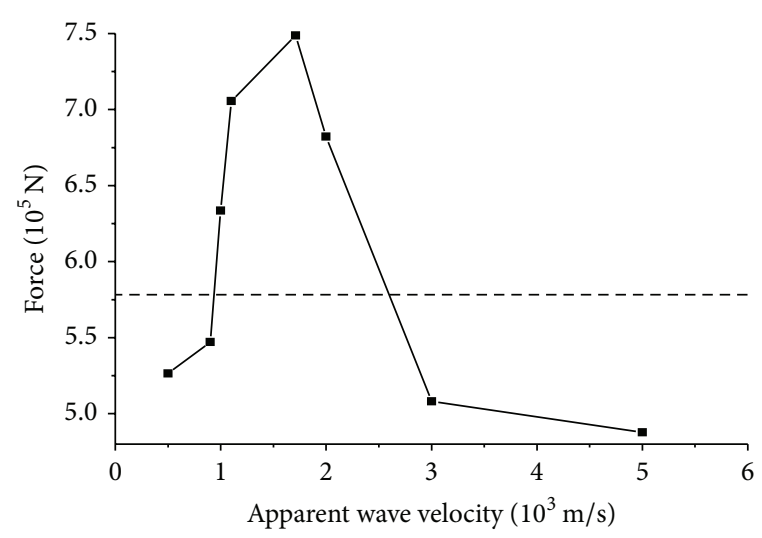

(b) Variation trend of $F_{P 2}$ with $c$

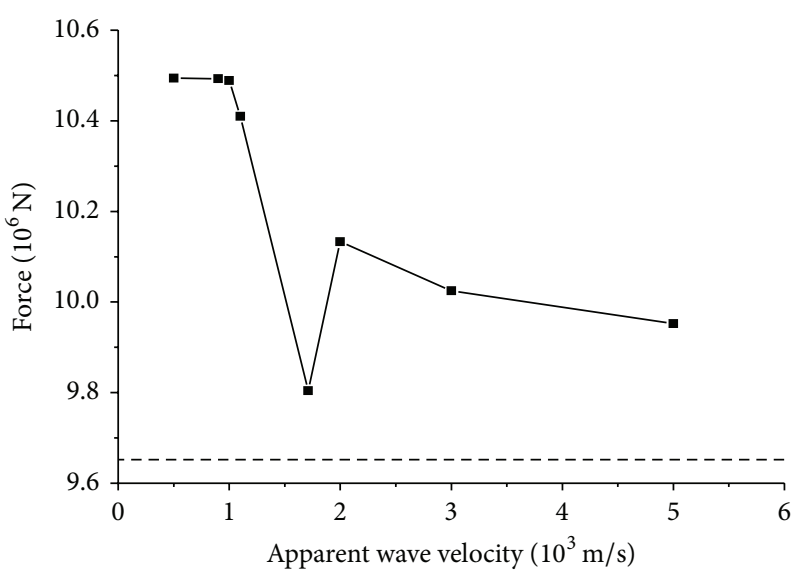

(d) Variation trend of $S_{T 1}$ with $c$

FIGURE 14: Variation trend of peak structural seismic responses with apparent wave velocity under the excitation of $c_{1}$.

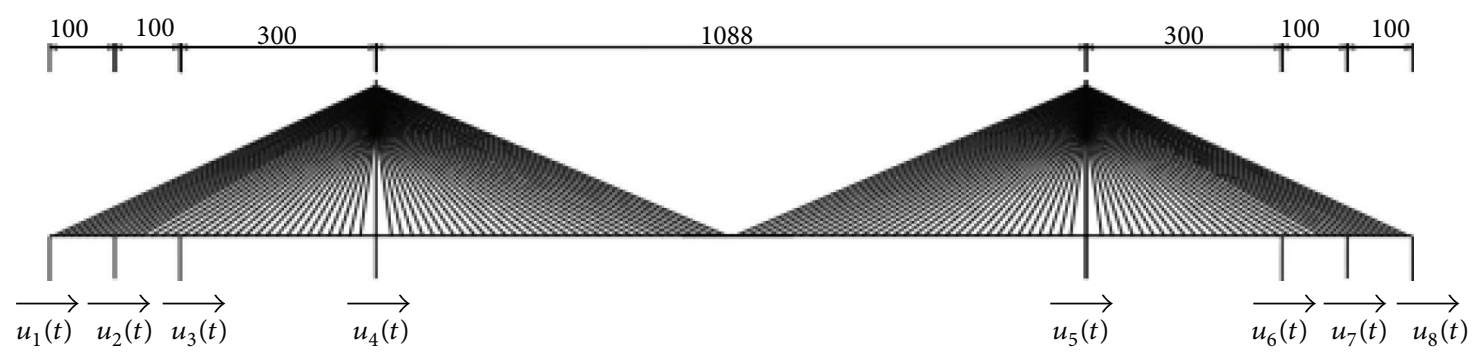

FIGURE 15: Full traveling time excitation method.

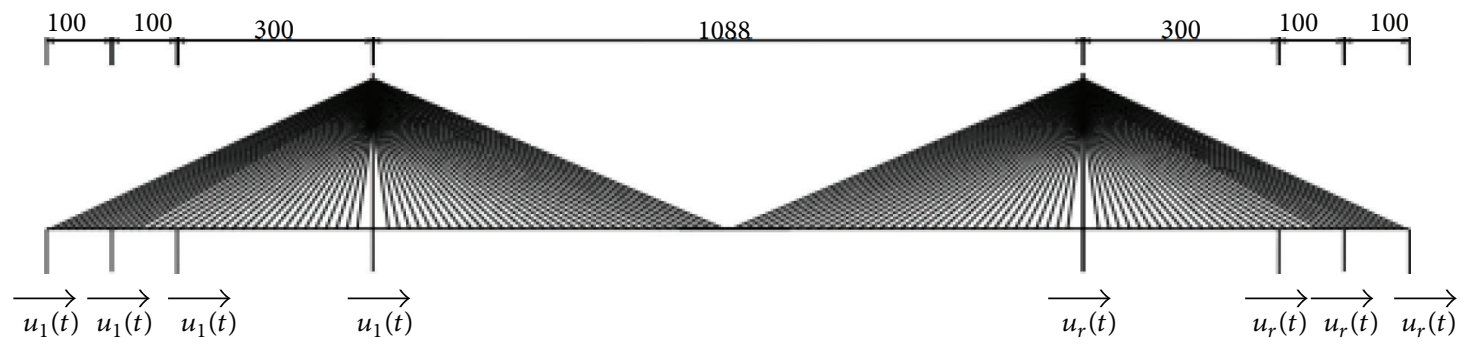

FIGURE 16: Grouping uniform excitation method. 


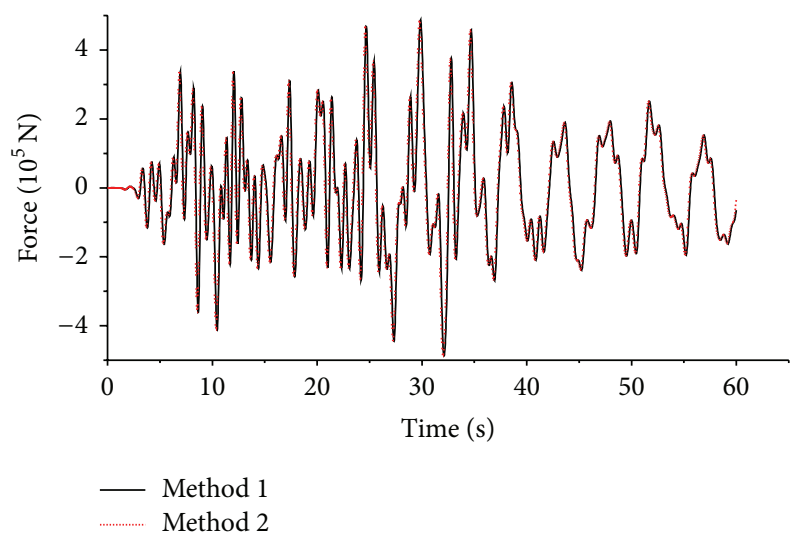

(a) $c=5000 \mathrm{~m} / \mathrm{s}$

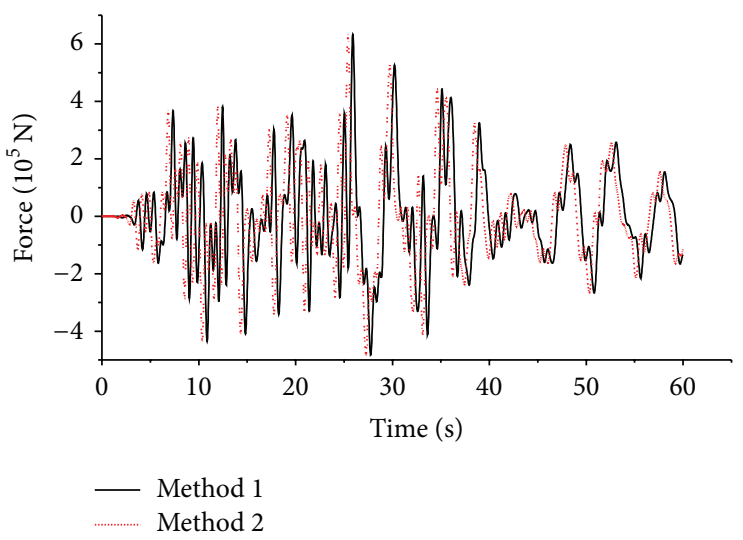

(b) $c=1000 \mathrm{~m} / \mathrm{s}$

FIGURE 17: Time histories of $F_{P 2}$ under the excitation of $c_{3}$.

TABLE 6: Comparisons of the structural peak seismic responses under different excitation methods under the excitation of $a_{1}$.

\begin{tabular}{|c|c|c|c|c|c|c|c|c|c|}
\hline \multirow{3}{*}{ Responses } & \multicolumn{9}{|c|}{ Cases } \\
\hline & \multicolumn{3}{|c|}{$c=5000 \mathrm{~m} / \mathrm{s}$} & \multicolumn{3}{|c|}{$c=3000 \mathrm{~m} / \mathrm{s}$} & \multicolumn{3}{|c|}{$c=1000 \mathrm{~m} / \mathrm{s}$} \\
\hline & $\begin{array}{c}\text { Excitation } \\
\text { method } 1\end{array}$ & $\begin{array}{l}\text { Excitation } \\
\text { method } 2\end{array}$ & $e(\%)$ & $\begin{array}{c}\text { Excitation } \\
\text { method } 1\end{array}$ & $\begin{array}{c}\text { Excitation } \\
\text { method } 2\end{array}$ & $e(\%)$ & $\begin{array}{c}\text { Excitation } \\
\text { method } 1\end{array}$ & $\begin{array}{l}\text { Excitation } \\
\text { method } 2\end{array}$ & $e(\%)$ \\
\hline$U_{t}(\mathrm{~m})$ & 0.620 & 0.620 & 0.00 & 0.613 & 0.613 & 0.00 & 0.608 & 0.608 & 0.00 \\
\hline$A_{t}\left(\mathrm{~m} / \mathrm{s}^{2}\right)$ & 1.835 & 1.835 & 0.00 & 1.798 & 1.798 & 0.00 & 1.910 & 1.909 & -0.05 \\
\hline$U_{b}(\mathrm{~mm})$ & 2.450 & 2.450 & 0.00 & 2.300 & 2.300 & 0.00 & 2.330 & 2.330 & 0.00 \\
\hline$U_{c}(\mathrm{~cm})$ & 4.759 & 4.759 & 0.00 & 4.522 & 4.522 & 0.00 & 4.476 & 4.477 & 0.02 \\
\hline$F_{P 1}\left(10^{5} \mathrm{~N}\right)$ & 2.451 & 2.451 & 0.00 & 2.666 & 2.666 & 0.00 & 2.446 & 2.444 & -0.08 \\
\hline$M_{P 1}\left(10^{4} \mathrm{kN} \cdot \mathrm{m}\right)$ & 10.669 & 10.668 & -0.01 & 10.670 & 10.667 & -0.03 & 10.670 & 10.672 & 0.02 \\
\hline$S_{P 1}\left(10^{6} \mathrm{~N}\right)$ & 2.275 & 2.274 & -0.04 & 2.275 & 2.274 & -0.04 & 2.275 & 2.275 & 0.00 \\
\hline$F_{P 2}\left(10^{5} \mathrm{~N}\right)$ & 5.267 & 5.265 & -0.04 & 4.573 & 4.571 & -0.04 & 4.959 & 4.958 & -0.02 \\
\hline$M_{P 2}\left(10^{4} \mathrm{kN} \cdot \mathrm{m}\right)$ & 11.153 & 11.153 & 0.00 & 11.153 & 11.153 & 0.00 & 11.151 & 11.152 & 0.01 \\
\hline$S_{P 2}\left(10^{6} \mathrm{~N}\right)$ & 2.378 & 2.378 & 0.00 & 2.378 & 2.378 & 0.00 & 2.378 & 2.378 & 0.00 \\
\hline$F_{P 3}\left(10^{6} \mathrm{~N}\right)$ & 1.767 & 1.767 & 0.00 & 1.816 & 1.816 & 0.00 & 2.005 & 2.005 & 0.00 \\
\hline$M_{P 3}\left(10^{4} \mathrm{kN} \cdot \mathrm{m}\right)$ & 11.804 & 11.804 & 0.00 & 11.804 & 11.804 & 0.00 & 11.802 & 11.803 & 0.01 \\
\hline$S_{P 3}\left(10^{6} \mathrm{~N}\right)$ & 2.466 & 2.466 & 0.00 & 2.466 & 2.466 & 0.00 & 2.465 & 2.466 & 0.04 \\
\hline$F_{T 1}\left(10^{6} \mathrm{~N}\right)$ & 3.096 & 3.096 & 0.00 & 3.303 & 3.303 & 0.00 & 4.113 & 4.114 & 0.02 \\
\hline$M_{T 1}\left(10^{6} \mathrm{kN} \cdot \mathrm{m}\right)$ & 1.149 & 1.149 & 0.00 & 1.076 & 1.076 & 0.00 & 1.095 & 1.095 & 0.00 \\
\hline$S_{T 1}\left(10^{7} \mathrm{~N}\right)$ & 0.994 & 0.994 & 0.00 & 1.011 & 1.011 & 0.00 & 0.891 & 0.891 & 0.00 \\
\hline
\end{tabular}

methods are nearly identical except for a slight translation due to the starting times of the support motions.

Tables 6, 7, and 8 list the peak seismic responses under the two excitation methods. The results indicate that the two excitation methods lead to nearly identical responses, with the maximum absolute value of the relative error at $0.08 \%$. It is therefore acceptable to use the grouping uniform excitation in practice instead of the full traveling time excitation method.

The results demonstrate that only the wave passage time from one main tower to the other needs to be considered for long-span floating system cable-stayed bridges under longitudinal traveling wave excitation. The grouping uniform excitation method can significantly reduce work load with an acceptable error.

\section{Conclusions}

The seismic responses of a long-span floating system doubletower symmetrical cable-stayed bridge under longitudinal uniform excitation and traveling wave excitation are calculated in this paper, and three main conclusions are obtained through a comparison of the results.

(i) Responses that consider the traveling wave effect significantly differ from those under uniform support motions. The responses may be amplified under the excitation of one set of ground motions but reduced under the excitation of another set. Even when the input is certain, some responses may remain the same, some may be amplified, and others are reduced. 
TABLE 7: Comparisons of the structural peak seismic responses under different excitation methods under the excitation of $b_{1}$.

\begin{tabular}{|c|c|c|c|c|c|c|c|c|c|}
\hline \multirow{3}{*}{ Responses } & \multicolumn{9}{|c|}{ Cases } \\
\hline & \multicolumn{3}{|c|}{$c=5000 \mathrm{~m} / \mathrm{s}$} & \multicolumn{3}{|c|}{$c=3000 \mathrm{~m} / \mathrm{s}$} & \multicolumn{3}{|c|}{$c=1000 \mathrm{~m} / \mathrm{s}$} \\
\hline & $\begin{array}{c}\text { Excitation } \\
\text { method } 1\end{array}$ & $\begin{array}{c}\text { Excitation } \\
\text { method } 2\end{array}$ & $e(\%)$ & $\begin{array}{c}\text { Excitation } \\
\text { method } 1\end{array}$ & $\begin{array}{c}\text { Excitation } \\
\text { method } 2\end{array}$ & $e(\%)$ & $\begin{array}{c}\text { Excitation } \\
\text { method } 1\end{array}$ & $\begin{array}{c}\text { Excitation } \\
\text { method } 2\end{array}$ & $e(\%)$ \\
\hline$U_{t}(\mathrm{~m})$ & 0.727 & 0.727 & 0.00 & 0.725 & 0.725 & 0.00 & 0.674 & 0.674 & 0.00 \\
\hline$A_{t}\left(\mathrm{~m} / \mathrm{s}^{2}\right)$ & 2.734 & 2.734 & 0.00 & 2.599 & 2.599 & 0.00 & 2.698 & 2.697 & -0.04 \\
\hline$U_{b}(\mathrm{~mm})$ & 3.100 & 3.100 & 0.00 & 2.870 & 2.870 & 0.00 & 2.780 & 2.780 & 0.00 \\
\hline$U_{c}(\mathrm{~cm})$ & 5.874 & 5.873 & -0.02 & 5.506 & 5.506 & 0.00 & 5.165 & 5.165 & 0.00 \\
\hline$F_{P 1}\left(10^{5} \mathrm{~N}\right)$ & 3.945 & 3.945 & 0.00 & 3.531 & 3.532 & 0.03 & 3.692 & 3.693 & 0.03 \\
\hline$M_{P 1}\left(10^{5} \mathrm{kN} \cdot \mathrm{m}\right)$ & 1.243 & 1.243 & 0.00 & 1.243 & 1.243 & 0.00 & 1.242 & 1.243 & 0.08 \\
\hline$S_{P 1}\left(10^{6} \mathrm{~N}\right)$ & 2.698 & 2.698 & 0.00 & 2.699 & 2.698 & -0.04 & 2.699 & 2.699 & 0.00 \\
\hline$F_{P 2}\left(10^{5} \mathrm{~N}\right)$ & 6.751 & 6.750 & -0.01 & 7.061 & 7.061 & 0.00 & 6.832 & 6.831 & -0.01 \\
\hline$M_{P 2}\left(10^{5} \mathrm{kN} \cdot \mathrm{m}\right)$ & 1.280 & 1.280 & 0.00 & 1.281 & 1.281 & 0.00 & 1.280 & 1.280 & 0.00 \\
\hline$S_{P 2}\left(10^{6} \mathrm{~N}\right)$ & 2.856 & 2.856 & 0.00 & 2.856 & 2.856 & 0.00 & 2.854 & 2.855 & 0.04 \\
\hline$F_{P 3}\left(10^{6} \mathrm{~N}\right)$ & 2.071 & 2.071 & 0.00 & 2.056 & 2.056 & 0.00 & 1.889 & 1.889 & 0.00 \\
\hline$M_{P 3}\left(10^{5} \mathrm{kN} \cdot \mathrm{m}\right)$ & 1.354 & 1.354 & 0.00 & 1.355 & 1.354 & -0.07 & 1.354 & 1.354 & 0.00 \\
\hline$S_{P 3}\left(10^{6} \mathrm{~N}\right)$ & 2.965 & 2.965 & 0.00 & 2.966 & 2.966 & 0.00 & 2.964 & 2.965 & 0.03 \\
\hline$F_{T 1}\left(10^{6} \mathrm{~N}\right)$ & 3.885 & 3.885 & 0.00 & 4.493 & 4.493 & 0.00 & 5.079 & 5.079 & 0.00 \\
\hline$M_{T 1}\left(10^{6} \mathrm{kN} \cdot \mathrm{m}\right)$ & 1.461 & 1.461 & 0.00 & 1.352 & 1.352 & 0.00 & 1.319 & 1.319 & 0.00 \\
\hline$S_{T 1}\left(10^{7} \mathrm{~N}\right)$ & 1.501 & 1.501 & 0.00 & 1.526 & 1.526 & 0.00 & 1.294 & 1.294 & 0.00 \\
\hline
\end{tabular}

TABLE 8: Comparisons of the structural peak seismic responses under different excitation methods under the excitation of $c_{1}$.

\begin{tabular}{|c|c|c|c|c|c|c|c|c|c|}
\hline \multirow{3}{*}{ Responses } & \multicolumn{9}{|c|}{ Cases } \\
\hline & \multicolumn{3}{|c|}{$c=5000 \mathrm{~m} / \mathrm{s}$} & \multicolumn{3}{|c|}{$c=3000 \mathrm{~m} / \mathrm{s}$} & \multicolumn{3}{|c|}{$c=1000 \mathrm{~m} / \mathrm{s}$} \\
\hline & $\begin{array}{c}\text { Excitation } \\
\text { method } 1\end{array}$ & $\begin{array}{l}\text { Excitation } \\
\text { method } 2\end{array}$ & $e(\%)$ & $\begin{array}{c}\text { Excitation } \\
\text { method } 1\end{array}$ & $\begin{array}{c}\text { Excitation } \\
\text { method } 2\end{array}$ & $e(\%)$ & $\begin{array}{c}\text { Excitation } \\
\text { method } 1\end{array}$ & $\begin{array}{c}\text { Excitation } \\
\text { method } 2\end{array}$ & $e(\%)$ \\
\hline$\overline{U_{t}(\mathrm{~m})}$ & 0.676 & 0.676 & 0.00 & 0.676 & 0.676 & 0.00 & 0.663 & 0.663 & 0.00 \\
\hline$A_{t}\left(\mathrm{~m} / \mathrm{s}^{2}\right)$ & 1.881 & 1.881 & 0.00 & 1.919 & 1.919 & 0.00 & 2.106 & 2.105 & -0.05 \\
\hline$U_{b}(\mathrm{~mm})$ & 2.190 & 2.190 & 0.00 & 2.120 & 2.120 & 0.00 & 2.340 & 2.340 & 0.00 \\
\hline$U_{c}(\mathrm{~cm})$ & 4.182 & 4.182 & 0.00 & 4.098 & 4.099 & 0.02 & 4.361 & 4.361 & 0.00 \\
\hline$F_{P 1}\left(10^{5} \mathrm{~N}\right)$ & 2.628 & 2.628 & 0.00 & 2.476 & 2.478 & 0.08 & 3.155 & 3.154 & -0.03 \\
\hline$M_{P 1}\left(10^{5} \mathrm{kN} \cdot \mathrm{m}\right)$ & 1.060 & 1.060 & 0.00 & 1.060 & 1.060 & 0.00 & 1.060 & 1.060 & 0.00 \\
\hline$S_{P 1}\left(10^{6} \mathrm{~N}\right)$ & 2.361 & 2.361 & 0.00 & 2.361 & 2.361 & 0.00 & 2.361 & 2.362 & 0.04 \\
\hline$F_{P 2}\left(10^{5} \mathrm{~N}\right)$ & 4.878 & 4.879 & 0.02 & 5.081 & 5.081 & 0.00 & 6.336 & 6.332 & -0.06 \\
\hline$M_{P 2}\left(10^{5} \mathrm{kN} \cdot \mathrm{m}\right)$ & 1.003 & 1.003 & 0.00 & 1.003 & 1.003 & 0.00 & 1.001 & 1.001 & 0.00 \\
\hline$S_{P 2}\left(10^{6} \mathrm{~N}\right)$ & 2.283 & 2.283 & 0.00 & 2.283 & 2.283 & 0.00 & 2.281 & 2.283 & 0.09 \\
\hline$F_{P 3}\left(10^{6} \mathrm{~N}\right)$ & 2.099 & 2.099 & 0.00 & 2.198 & 2.198 & 0.00 & 2.246 & 2.246 & 0.00 \\
\hline$M_{P 3}\left(10^{5} \mathrm{kN} \cdot \mathrm{m}\right)$ & 1.054 & 1.054 & 0.00 & 1.054 & 1.054 & 0.00 & 1.053 & 1.053 & 0.00 \\
\hline$S_{P 3}\left(10^{6} \mathrm{~N}\right)$ & 2.379 & 2.379 & 0.00 & 2.379 & 2.379 & 0.00 & 2.380 & 2.380 & 0.00 \\
\hline$F_{T 1}\left(10^{6} \mathrm{~N}\right)$ & 4.369 & 4.369 & 0.00 & 4.827 & 4.827 & 0.00 & 4.275 & 4.275 & 0.00 \\
\hline$M_{T 1}\left(10^{6} \mathrm{kN} \cdot \mathrm{m}\right)$ & 1.036 & 1.036 & 0.00 & 1.001 & 1.001 & 0.00 & 1.110 & 1.110 & 0.00 \\
\hline$S_{T 1}\left(10^{6} \mathrm{~N}\right)$ & 9.952 & 9.952 & 0.00 & 10.025 & 10.025 & 0.00 & 10.489 & 10.487 & -0.02 \\
\hline
\end{tabular}

To guarantee the safety of the bridge, the traveling wave effect should be given sufficient attention in the seismic design of long-span cable-stayed bridges.

(ii) The bridge's seismic responses do not vary monotonously with the apparent wave velocity due to the traveling wave resonance. The responses may obtain an extreme value, or even a maxima and minima, at specific apparent wave velocities. This phenomenon is more remarkable when the frequency of the modes at the resonance state is within the predominant frequency range of the seismic wave.

(iii) When only considering the seismic excitation in the longitudinal direction for a long-span floating system cable-stayed bridge, we can ignore the traveling time 
from the far left pier to the left tower and from the right tower to the far right pier and only consider the wave passage time from the left tower to the right tower.

\section{Conflict of Interests}

The authors declare that there is no conflict of interests regarding the publication of this paper.

\section{Acknowledgments}

This work is supported by the National Natural Science Foundation of China (Grant no. 91315301) and the State Key Laboratory Theory Foundation of the Ministry of Science and Technology of China (Grant no. SLDRCE08-A-07). These supports are gratefully acknowledged.

\section{References}

[1] J. L. Bogdanoff, J. E. Goldberg, and A. J. Schiff, "The effect of ground transmission time on the response of long structures," Bulletin of the Seismological Society of America, vol. 5, no. 3, pp. 627-640, 1965.

[2] R. Betti, A. M. Abdel-Ghaffar, and A. S. Niazy, "Kinematic soilstructure interaction for long-span cable-supported bridges," Earthquake Engineering \& Structural Dynamics, vol. 22, no. 5, pp. 415-430, 1993.

[3] C.-Y. Jiao, J.-Z. Li, and T.-B. Peng, "Effects of different connecting styles between towers and deck on seismic responses of a long-span cable-stayed bridge," Journal of Vibration and Shock, vol. 28, no. 10, pp. 179-184, 2009.

[4] G. M. Calvi, T. J. Sullivan, and A. Villani, "Conceptual seismic design of cable-stayed bridges," Journal of Earthquake Engineering, vol. 14, no. 8, pp. 1139-1171, 2010.

[5] A. Camara and M. A. Astiz, "Pushover analysis for the seismic response prediction of cable-stayed bridges under multidirectional excitation," Engineering Structures, vol. 41, pp. 444455,2012

[6] A. Zerva, "Effect of spatial variability and propagation of seismic ground motions on the response of multiply supported structures," Probabilistic Engineering Mechanics, vol. 6, no. 3-4, pp. 212-221, 1991.

[7] R. S. Harichandran, A. Hawwari, and B. N. Sweidan, "Response of long-span bridges to spatially varying ground motion a," Journal of Structural Engineering, vol. 122, no. 5, pp. 476-484, 1996.

[8] M. Lou, Q. Li, and S. Gao, "Response analysis of a longspan arch bridge under the seismic traveling excitation," in Proceedings of the International Conference on Seismic Design of Industrial Facilities, Aachen, Germany, October 2013.

[9] S. M. Allam and T. K. Datta, "Seismic behaviour of cable-stayed bridges under multi-component random ground motion," Engineering Structures, vol. 21, no. 1, pp. 62-74, 1999.

[10] S. Ates, A. A. Dumanoglu, and A. Bayraktar, "Stochastic response of seismically isolated highway bridges with friction pendulum systems to spatially varying earthquake ground motions," Engineering Structures, vol. 27, no. 13, pp. 1843-1858, 2005.

[11] S. Ates, A. Bayraktar, and A. A. Dumanoglu, "The effect of spatially varying earthquake ground motions on the stochastic response of bridges isolated with friction pendulum systems," Soil Dynamics and Earthquake Engineering, vol. 26, no. 1, pp. 31-44, 2006.

[12] F. W. Wu, Study of long span cable-stayed bridges stochastic seismic response and dynamic reliability [Ph.D. thesis], Southwest Jiaotong University, Chengdu, China, 2008.

[13] H. M. Ali and A. M. Abdel-Ghaffar, "Seismic passive control of cable-stayed bridges," Shock and Vibration, vol. 2, no. 4, pp. 259272, 1995.

[14] H.-J. Jung, K.-S. Park, B. F. Spencer Jr., and I.-W. Lee, “Hybrid seismic protection of cable-stayed bridges," Earthquake Engineering and Structural Dynamics, vol. 33, no. 7, pp. 795-820, 2004.

[15] C.-M. Chang and C.-H. Loh, "Seismic response control of cable-stayed bridge using different control strategies," Journal of Earthquake Engineering, vol. 10, no. 4, pp. 481-508, 2006.

[16] M. H. El Ouni and N. Ben Kahla, "Numerical study of the active tendon control of a cable-stayed bridge in a construction phase," Shock and Vibration, vol. 2014, Article ID 937541, 10 pages, 2014.

[17] P. Clemente, F. Marulo, L. Lecce, and A. Bifulco, "Experimental modal analysis of the Garigliano cable-stayed bridge," Soil Dynamics and Earthquake Engineering, vol. 17, no. 7-8, pp. 485493, 1998.

[18] G. Heo, C. Kim, and C. Lee, "Experimental test of asymmetrical cable-stayed bridges using MR-damper for vibration control," Soil Dynamics and Earthquake Engineering, vol. 57, pp. 78-85, 2014.

[19] L. J. Dong and X. B. Li, “Three-dimensional analytical solution of acoustic emission or microseismic source location under cube monitoring network," Transactions of Nonferrous Metals Society of China, vol. 22, no. 12, pp. 3087-3094, 2012.

[20] L. Dong and X. Li, "A microseismic/acoustic emission source location method using arrival times of PS waves for unknown velocity system," International Journal of Distributed Sensor Networks, vol. 2013, Article ID 307489, 8 pages, 2013.

[21] L. Dong, X. Li, and G. Xie, "An analytical solution for acoustic emission source location for known P wave velocity system," Mathematical Problems in Engineering, vol. 2014, Article ID 290686, 6 pages, 2014.

[22] X. Li and L. Dong, "An efficient closed-form solution for acoustic emission source location in three-dimensional structures," AIP Advances, vol. 4, no. 2, 8 pages, 2014.

[23] L. Dong, X. Li, and G. Xie, "Nonlinear methodologies for identifying seismic event and nuclear explosion using random forest, support vector machine, and naive Bayes classification," Abstract and Applied Analysis, vol. 2014, Article ID 459137, 8 pages, 2014.

[24] R. Clough and J. Penzien, Dynamics of Structures, McGraw-Hill, New York, NY, USA, 1975.

[25] A. D. Kiureghian, P. Keshishian, and A. Hakobian, "Multiplesupport response spectrum analysis of the bridges including the site response effect and the MSRS code," Tech. Rep. UCB/EERC97/02, Earthquake Engineering Research Center, University of California, Berkeley, Calif, USA, 1997.

[26] M. Lou and S. Gao, "The resonant effect of traveling wave for the arch bridge under vertical seismic excitation," World Information on Earthquake Engineering, vol. 25, no. 4, pp. 7-11, 2009.

[27] L. Xu and X.-X. Zheng, "Seismic response of long-span cable stayed bridge under asynchronous excitations," Journal of Fuzhou University (Natural Science Edition), vol. 41, no. 4, pp. 528-533, 2013. 

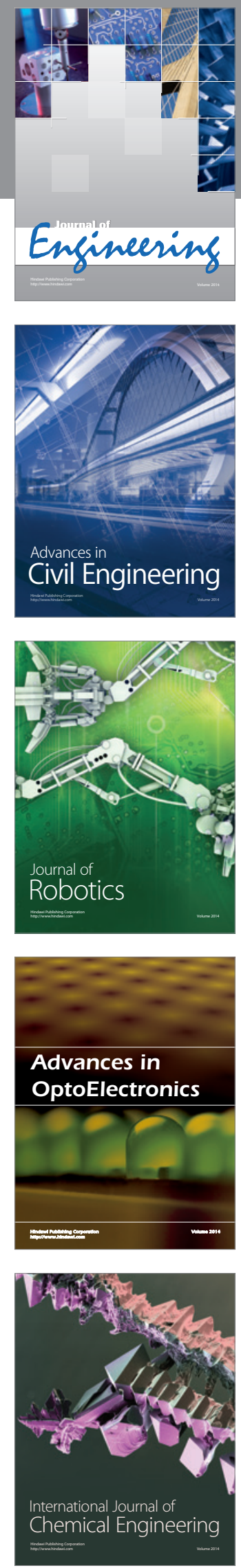

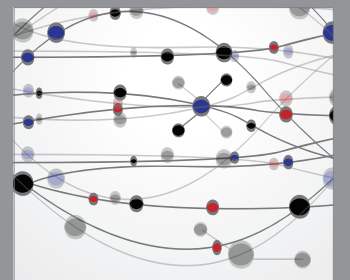

The Scientific World Journal
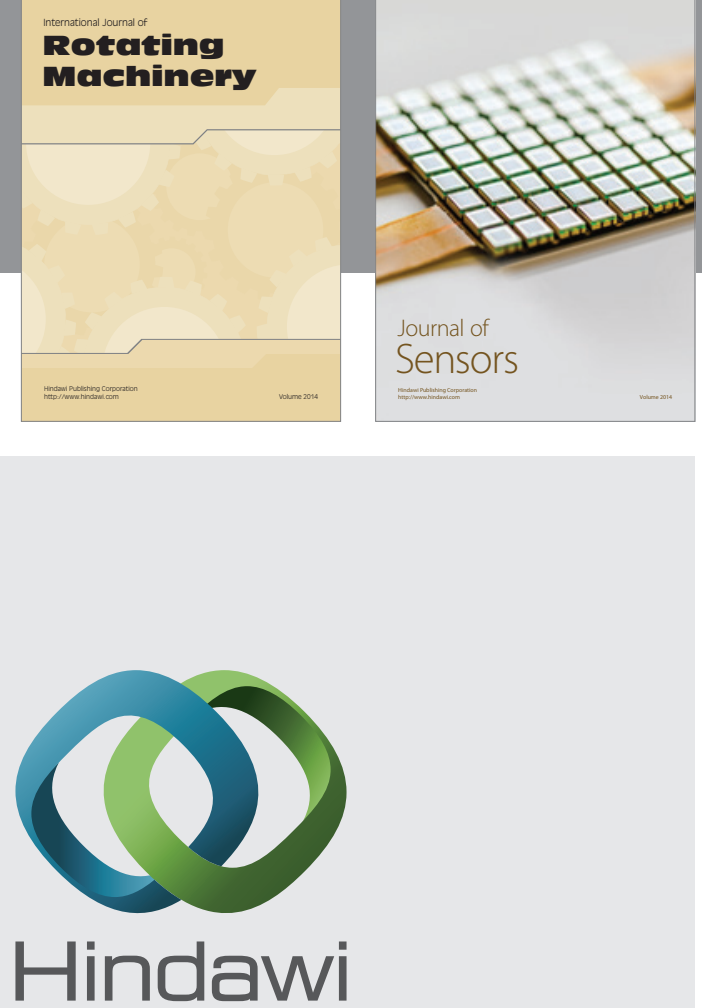

Submit your manuscripts at http://www.hindawi.com
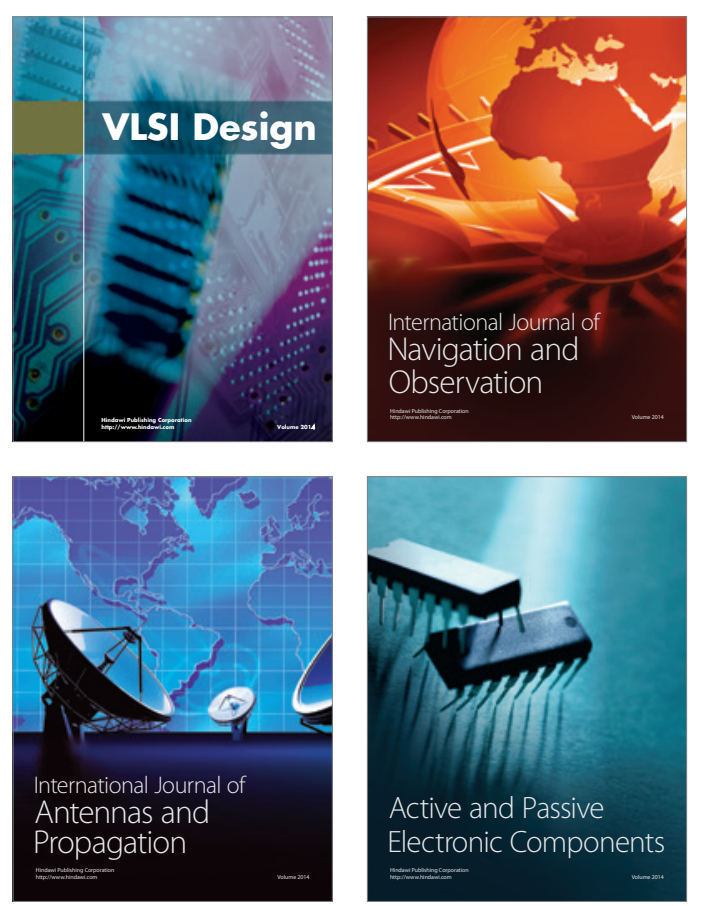
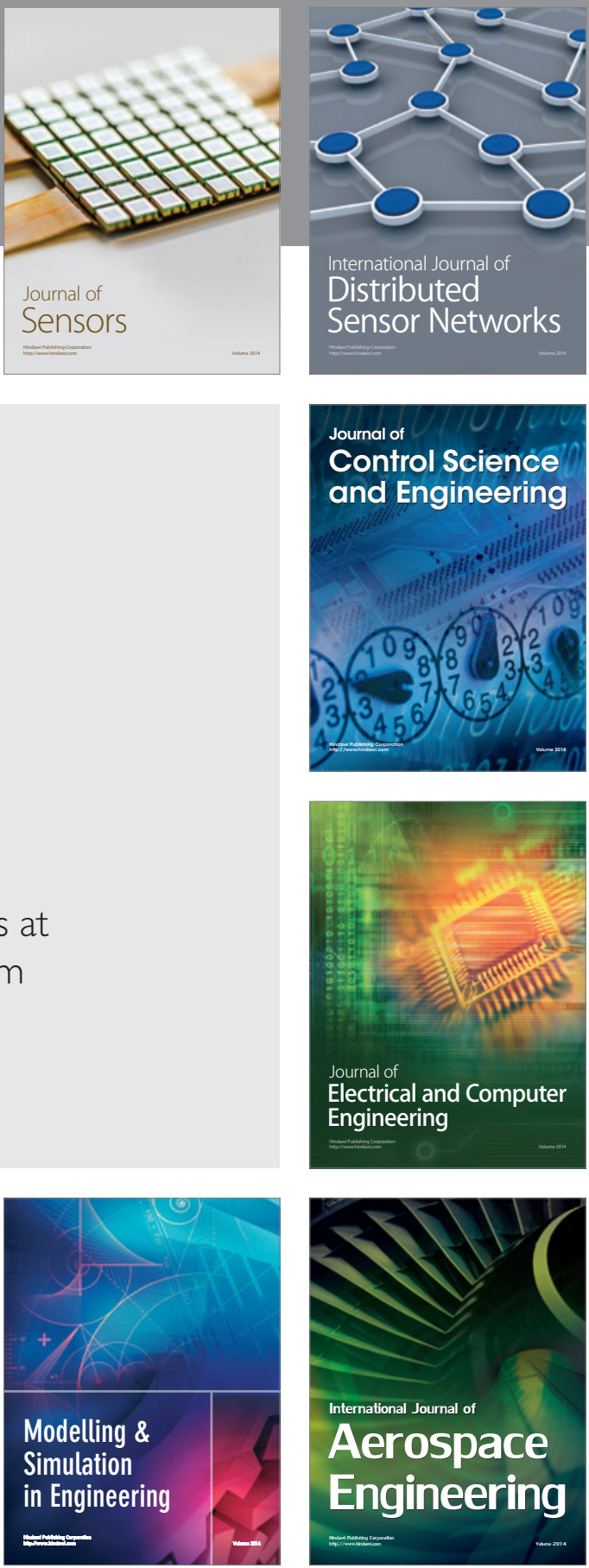

Journal of

Control Science

and Engineering
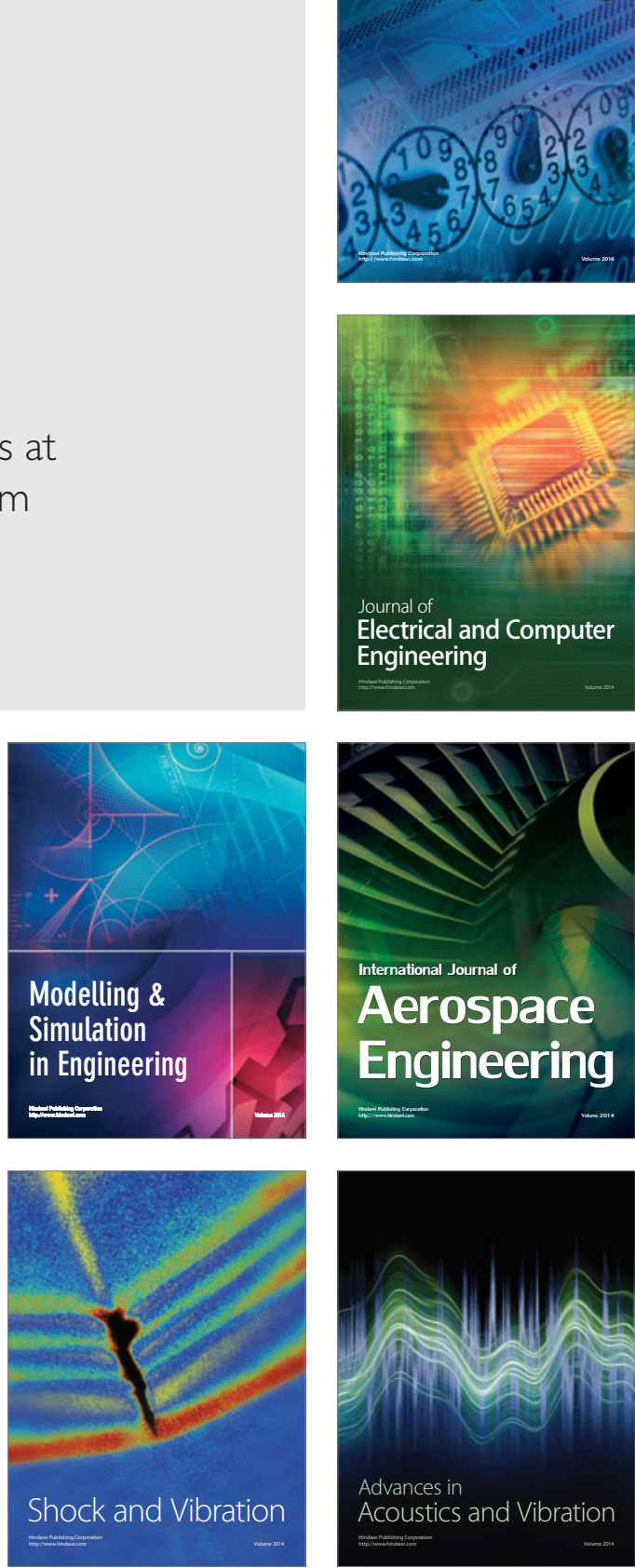